\title{
Systemic immunity in cancer
}

Kamir J. Hiam-Galvez ${ }^{1,2,3,4,5,6}$, Breanna M. Allen ${ }^{1,2,3,4,5,6}$ and Matthew H. Spitzer $\mathbb{1}^{1,2,3,4,5,6 凶}$

Abstract | Immunotherapy has revolutionized cancer treatment, but efficacy remains limited in most clinical settings. Cancer is a systemic disease that induces many functional and compositional changes to the immune system as a whole. Immunity is regulated by interactions of diverse cell lineages across tissues. Therefore, an improved understanding of tumour immunology must assess the systemic immune landscape beyond the tumour microenvironment (TME). Importantly, the peripheral immune system is required to drive effective natural and therapeutically induced antitumour immune responses. In fact, emerging evidence suggests that immunotherapy drives new immune responses rather than the reinvigoration of pre-existing immune responses. However, new immune responses in individuals burdened with tumours are compromised even beyond the TME. Herein, we aim to comprehensively outline the current knowledge of systemic immunity in cancer.

Peripheral immune cells Immune cells in an individual bearing a tumour that are not in the tumour microenvironment.

\section{'Department of} Otolaryngology - Head and Neck Surgery, University of California, San Francisco, San Francisco, CA, USA.

${ }^{2}$ Department of Microbiology \& Immunology, University of California, San Francisco, San Francisco, CA, USA.

${ }^{3}$ Graduate Program in Biomedical Sciences, University of California, San Francisco, San Francisco, CA, USA.

${ }^{4}$ Helen Diller Family Comprehensive Cancer Center, University of California, San Francisco, San Francisco, CA, USA.

${ }^{5}$ Parker Institute for Cancer Immunotherapy, San Francisco, CA, USA.

${ }^{6}$ Chan Zuckerberg Biohub,

San Francisco, San Francisco, CA, USA.

凶e-mail:matthew.spitzer@ ucsf.edu

https://doi.org/10.1038/ \$41568-021-00347-z
Cancer is a systemic disease, and prolonged inflammation is a hallmark of cancer ${ }^{1}$. Whether this inflammation initiates tumorigenesis or supports tumour growth is context dependent, but ultimately the global immune landscape beyond the tumour becomes significantly altered during tumour progression. Over the last decade, targeting the immune system with immunotherapy has revolutionized cancer therapy. Modulation of the existing patient immune system through immune checkpoint inhibitors (ICIs) such as anti-CTLA4, anti-PD1 and anti-PDL1 has led to durable remissions across a wide variety of different tumour types. Moreover, infusion of expanded autologous tumour-specific T cells or chimeric antigen receptor $\mathrm{T}$ cells has proven effective in patients with leukaemia. Despite these successes, immunotherapy remains ineffective for most patients with cancer ${ }^{2,3}$. To date, most immunotherapies have largely been used in patients with advanced cancers, and therefore the response rate in less advanced disease remains to be fully determined. Further progress towards more broadly effective immunotherapeutic strategies requires a deeper understanding of the immunological relationships between tumours and their hosts across the body.

The tumour immunology field has focused heavily on local immune responses in the tumour microenvironment (TME), yet immunity is coordinated across tissues. For example, many myeloid cells are frequently replenished from haematopoietic precursors in the bone marrow $^{4}$, and critical $\mathrm{T}$ cell priming events typically occur in lymphoid tissues ${ }^{5}$. The localized antitumour immune response cannot exist without continuous communication with the periphery. Furthermore, virtually every subset of immune cell has been implicated in cancer biology $y^{6,7}$. Therefore, a thorough understanding of immune responses to cancer must encompass all immune cell lineages across the peripheral immune system in addition to within the TME.

Recent clinical and preclinical studies are beginning to unravel the range of systemic immune perturbations that occur during tumour development as well as the crucial contribution of peripheral immune cells to an antitumour immune response. Here, we review recent advances that set the stage for a new holistic vantage point of tumour immunology to map and therapeutically harness the entirety of an immune response to cancer. We outline the extensive reorganization of peripheral immune cells that coincides with malignant tumour outgrowth as well as the systemic immunological consequences of conventional therapies (surgery, chemotherapy, radiation). We also examine the critical contribution of peripheral immune cells to driving and sustaining efficacious immunotherapy responses and the capacity of the tumour-burdened immune system to orchestrate a new immune response. Finally, we address the utility of peripheral immune biomarkers in aiding the diagnosis and prognosis of cancer and response to therapy.

\section{Perturbations induced by tumour burden}

Many human cancers and mouse models of cancer drive extensive disruption of haematopoiesis. This disruption manifests most prominently in an expansion of immature neutrophils and monocytes in the periphery of tumour-burdened hosts, which then also traffic to the TME and contribute to local immunosuppression. This phenomenon has been reviewed extensively elsewhere ${ }^{8-10}$. In brief, haematopoietic stem and progenitor cells are mobilized into proliferation and differentiation towards the monocytic and granulocytic lineages, resulting in peripheral expansion and intratumoural 
Immune macroenvironment

The total immune system

in a tumour-burdened host

comprising blood and

secondary lymphoid organs

such as the bone marrow,

spleen and lymph nodes.

Co-stimulatory and co-inhibitory receptors

Immunological receptors expressed on the surface of lymphocytes, antigenpresenting cells and tumour cells that stimulate or inhibit immune cell functions.

Lymphopenia The reduced abundance of lymphocytes ( $T$ cells and/or B cells and/or natural killer cells) in the blood. accumulation of immature immunosuppressive neutrophils (often referred to as polymorphonuclear myeloidderived suppressor cells (PMN-MDSCs)), monocytes (often referred to as M-MDSCs) and macrophages ${ }^{11-15}$ (FIG. 1). Mouse models of breast cancer and rhabdomyosarcoma have demonstrated that the frequency of bone marrow haematopoietic stem cells, multipotent progenitors and granulocyte monocyte progenitors progressively increase with the tumour burden ${ }^{12,16-18}$. Importantly, a pan-cancer study found elevated levels of haematopoietic stem cells, multipotent progenitors and granulocyte monocyte progenitors in the blood of patients with breast, cervical, liver, oesophageal, lung, ovarian and gastrointestinal cancers, suggesting that haematopoietic dysregulation is common in human cancer ${ }^{13}$. A comprehensive meta-analysis of more than 40,000 patients found that elevated neutrophil frequencies in the blood, as measured by the neutrophil to lymphocyte ratio, were associated with poor prognosis in patients with mesothelioma, pancreatic cancer, renal cell carcinoma, colorectal carcinoma, gastroesophageal cancer, non-small-cell lung cancer (NSCLC), cholangiocarcinoma and hepatocellular carcinoma ${ }^{19}$. Several factors have been implicated in driving this process including G-CSF ${ }^{12,20}$, GM-CSF ${ }^{17,21,22}$, IL-17 $\left(\right.$ REF. $\left.^{15}\right)$, oxysterol ${ }^{23}$, IL-8 (REF. ${ }^{24}$ ), CCL2 (REF. ${ }^{14}$ ), TNF ${ }^{25}$, tumour-derived exosomes ${ }^{26}$ and IL- $1 \beta\left(\right.$ REF. $\left.^{27}\right)$.

The vast majority of research that highlights peripheral immune perturbations in the context of cancer has focused on this increase in immature and immunosuppressive myeloid populations; however, this expansion also often co-occurs with alterations to many other peripheral immune lineages (FIG. 1). Our group recently used mass cytometry to comprehensively profile the phenotype and frequency of all major immune lineages in the bone marrow, spleen, blood, draining lymph node ( $\mathrm{dLN})$ and tumour in eight distinct mouse tumour models ${ }^{28}$. Although we observed a peripheral myeloid expansion in all tumour models as has been previously described, we also observed extensive peripheral immune reorganization across lineages and tissues. For example, three models of breast cancer (AT3, 4T1, MMTV-PyMT) spanning three different mouse strain backgrounds showed extensive splenic immune population remodelling characterized by phenotypic shifts as well as increased frequencies of neutrophils, eosinophils and monocytes along with reductions in dendritic cell, $\mathrm{B}$ cell and $\mathrm{T}$ cell populations (FIG. 1). Strikingly, surgical resection of the tumour or cytokine blockade treatments reversed many of the changes, suggesting plasticity in the peripheral reorganization of the immune macroenvironment in cancer. These data demonstrate that tumour development dramatically restructures the global immune landscape across immune cell lineages.

Beyond excessive production of monocytic and neutrophilic cells through aberrant haematopoiesis, perturbations in dendritic cells have been observed in the periphery of tumour-burdened hosts. This has important implications for the development of antitumour immune responses, as dendritic cells are critical orchestrators of $\mathrm{CD}^{+}$and $\mathrm{CD} 4^{+} \mathrm{T}$ cell priming, differentiation and proliferation in many contexts, including cancer ${ }^{29,30}$. The frequencies of dendritic cell subsets are decreased in peripheral blood of human ovarian ${ }^{31}$, prostate $^{31}$, breast ${ }^{32}$, lung ${ }^{33}$ and renal ${ }^{34}$ cancers as well as head and neck squamous cell carcinoma ${ }^{35}$ and melanoma ${ }^{36}$ when compared with healthy control donors (FIG. 1). In patients with pancreatic or breast cancer and in mouse models of these cancer types, a decrease in the frequency of peripheral type 1 conventional dendritic cells ( $\mathrm{cDC} 1 \mathrm{~s})$ was driven through tumour-derived G-CSF, which caused a downregulation of IRF8 in dendritic cell precursors, reducing the differentiation of mature dendritic cells ${ }^{18}$ (FIG. 1). Similarly, tumour-derived vascular endothelial growth factor (VEGF) has been shown to inhibit the maturation of dendritic cell precursors ${ }^{37,38}$. An alternative mechanism for dendritic cell paucity in a mouse model of pancreatic cancer was shown to be mediated by serum IL-6 driving increased dendritic cell apoptosis ${ }^{39}$ (FIG. 1). In patients with pancreatic cancer and mouse models of pancreatic cancer, peripheral dendritic cells differentiate into a semi-mature state characterized by moderate increases in co-stimulatory and co-inhibitory receptors ${ }^{39-41}$ (FIG. 1). Bulk transcriptomic analyses of these peripheral dendritic cells from mice bearing pancreatic tumours revealed that these semi-mature dendritic cells showed upregulation of genes involved in proteasomal degradation but did not show upregulation of $\mathrm{T}$ cell polarizing cytokines $^{39}$, suggesting that, similar to semi-mature dendritic cells in other contexts, they only partially possess the capacity to provide stimulation to T cells.

Substantially less is known about the organization of other major immune lineages in the tumour macroenvironment. Lymphopenia is common in patients with breast cancer, lymphoma and sarcoma ${ }^{42}$. Interestingly, circulating $\mathrm{T}$ cells in patients with breast ${ }^{43}$ lung $^{44}$ and cervical ${ }^{45}$ cancers have decreased diversity in the repertoire of $\mathrm{T}$ cell receptors (TCRs) (FIG. 1). As greater TCR diversity is associated with better tumour control in patients with melanoma ${ }^{46}$, an improved understanding of TCR repertoire fluctuations driven by cancer is warranted. Furthermore, as a decreased TCR repertoire in humans is associated with age ${ }^{47}$ as well as other prior immunological exposures such as chronic infection ${ }^{48}$, these changes may also be a cause for malignant outgrowth. The causal relationship between TCR diversity and cancer has yet to be determined. Peripheral T cells are also functionally perturbed, as polyclonal memory $\mathrm{CD}^{+}$and $\mathrm{CD}^{+}$ $\mathrm{T}$ cells from peripheral blood have decreased capacity to produce IL- 2 and IFN $\gamma$ in response to stimulation with PMA and ionomycin in human patients with breast cancer $^{49}$. Peripheral naive $\mathrm{CD} 4^{+} \mathrm{T}$ cells also exhibited decreased responses to IL- 6 stimulation as measured by phosphorylation of STAT1 and STAT3 in patients with breast $\operatorname{cancer}^{50}$ (FIG. 1).

The most studied perturbation of $\mathrm{T}$ cells in cancer is the expansion of suppressive $\mathrm{CD} 4^{+}$regulatory $\mathrm{T}\left(\mathrm{T}_{\mathrm{reg}}\right)$ cells in the periphery and their infiltration into the tumour ${ }^{51}$. Recent work has now shown that $\mathrm{T}_{\text {reg }}$ cells present in the blood of patients with cancer share phenotypic and TCR repertoires with intratumoural T cells, suggesting that a significant proportion of intratumoural suppressive $\mathrm{T}_{\text {reg }}$ cells are derived from naturally occurring 


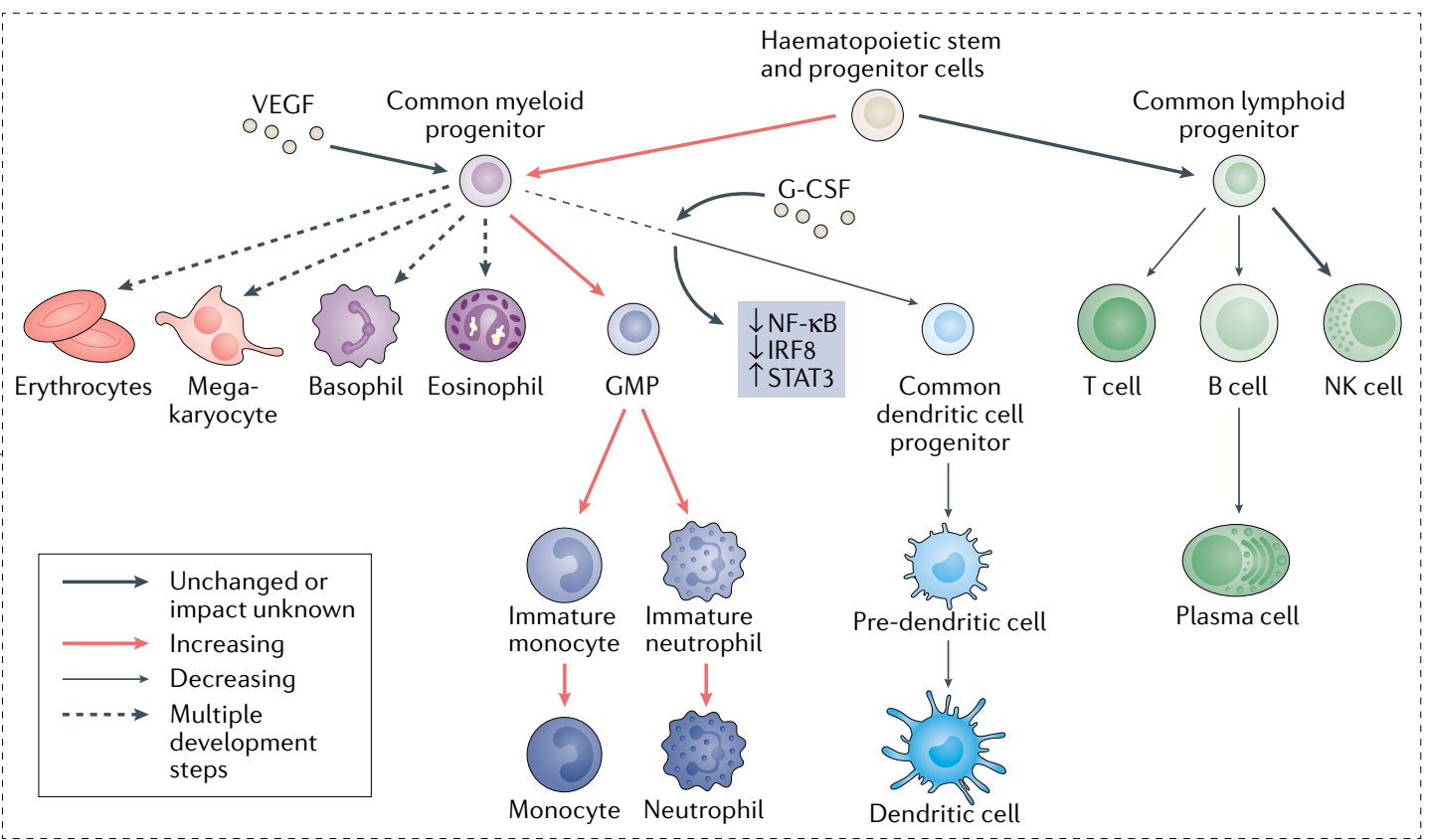

b

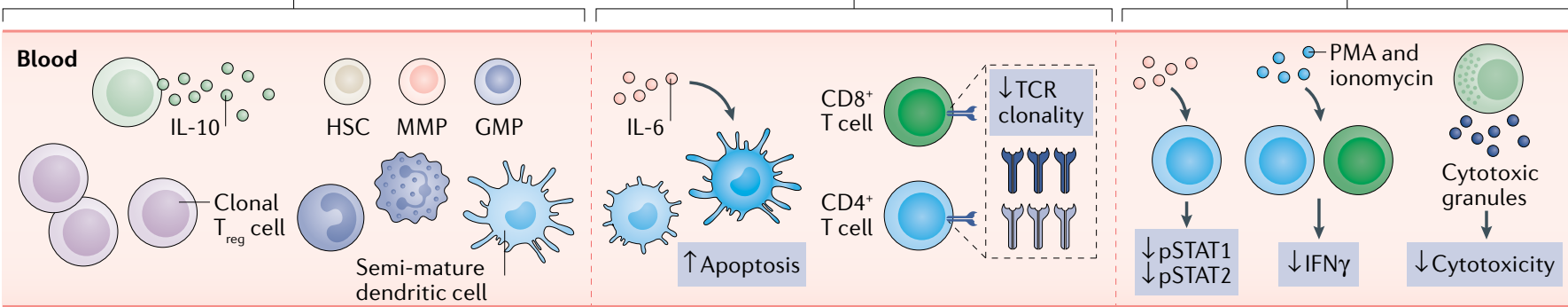

\section{c Spleen}

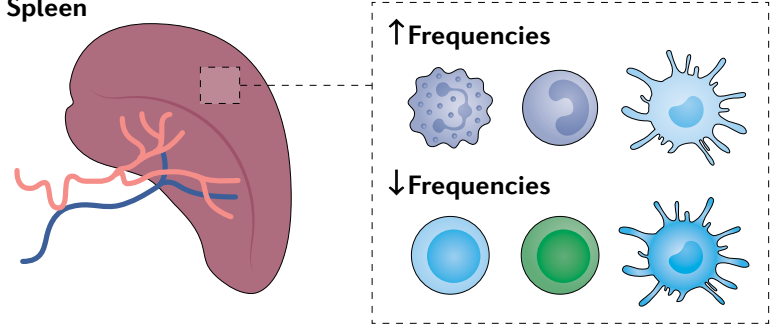

d Tumour dLN

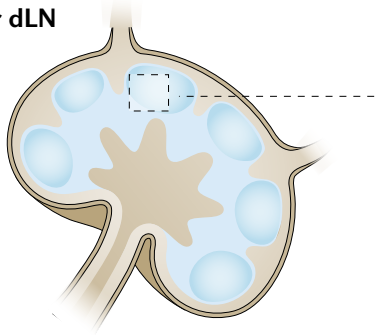

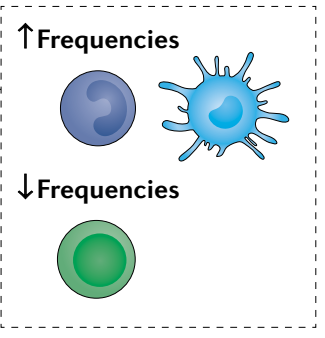

Fig. 1 Systemic perturbations to immune organization by the tumour burden. The peripheral immune landscape is perturbed in many tumour types. The bone marrow, blood, spleen and draining lymph node (dLN) form an immunological network in constant communication during tumour development. a | Bone marrow haematopoiesis skews towards the production of neutrophils and monocytes through increased frequency of haematopoietic stem cells (HSCs) and granulocyte monocyte progenitors (GMPs). In some contexts, this skewing occurs at the expense of dendritic cell precursors which share progenitors, leading to a systemic paucity of dendritic cells that has been shown to be driven by G-CSF stimulating STAT3 signalling while repressing IRF8, as well as through vascular endothelial growth factor (VEGF) decreasing $\mathrm{NF}-\kappa \mathrm{B}$ signalling. T cell, B cell and plasma cell populations in the bone marrow have also been shown to be decreased. b | During tumour development, bone marrow progenitor pools as well as suppressive immature monocytes and neutrophils are mobilized into circulation in the blood. Systemic increased frequencies of suppressive lymphocyte populations, $C D 4^{+}$regulatory $T\left(\mathrm{~T}_{\text {reg }}\right)$ cells and regulatory $\mathrm{B}$ cells are also commonly observed. $\mathrm{T}_{\text {reg }}$ cells specifically undergo clonal expansion in the periphery before infiltrating the tumour. Dendritic cell as well as $\mathrm{CD} 8^{+}$and $\mathrm{CD} 4^{+} \mathrm{T}$ cell frequencies and $\mathrm{T}$ cell receptor $(\mathrm{TCR})$ repertoire diversity are decreased in many tumour contexts. Functional deficits in response to stimuli have been identified in T cell populations. CD4 ${ }^{+}$ T cells exhibit decreased signalling responses to IL-6 stimulation, and both $\mathrm{CD}^{+}$and $\mathrm{CD} 8^{+} \mathrm{T}$ cells produce less IL-2 and IFN $\gamma$ in response to PMA and ionomycin stimulation. Natural killer (NK) cell cytotoxic potential is also decreased. $\mathbf{c}$ | Several alterations observed in the blood have been mirrored in the spleen in mouse models, including accumulation of immature neutrophils, monocytes and semi-mature dendritic cells. Decreased abundance of dendritic cells and T cell populations has also recently been described. $\mathbf{d}$ | The tumour dLN has the most direct line of communication with the tumour and is characterized by increased frequency of monocytes and dendritic cells with a decrease of $\mathrm{CD} 8^{+} \mathrm{T}$ cells. Collectively, these observations across many human and mouse tumour models demonstrate that the peripheral immune landscape is shifted towards a suppressive state marked by increases in anti-inflammatory cell types and decreases in key mediators of antitumour immunity. MMP, multipotent progenitor. 
thymic $\mathrm{T}_{\text {reg }}$ cells rather than through tumour-induced differentiation of naive $\mathrm{CD} 4^{+} \mathrm{T}$ cells $^{52,53}$ (FIG. 1).

Another suppressive lymphocyte population that plays a role in tumour progression is regulatory $\mathrm{B}$ cells, which are characterized by production of the anti-inflammatory cytokine IL-10 (REF. $\left.{ }^{54}\right)$. Similar to $\mathrm{T}_{\text {reg }}$ cells, an expansion of IL-10-producing regulatory $B$ cells has been documented in peripheral blood of patients with gastric cancer ${ }^{55,56}$ and patients with lung cancer $^{57}$, whereas frequencies of total B cells remained unchanged (FIG. 1). In the 4T1 mouse model of breast cancer, suppressive $\mathrm{CD} 25^{+}$regulatory B cells were expanded in the spleen, lymph nodes and blood ${ }^{58}$.

Natural killer (NK) cells are yet another important component of antitumour immunity that can directly kill tumour cells as well as influence antitumorigenic behaviour of other immune cells ${ }^{59}$. Peripheral NK cells from patients with breast cancer also have altered phenotypes, characterized by decreased expression of activating receptors, including NKp30, NKG2D, DNAM-1 and CD16, and increased expression of the inhibitory receptor NKG2A, as well as impaired capacity to directly kill target cells and degranulate in vitro ${ }^{60}$. In patients with gastrointestinal stromal tumours, peripheral NK cells showed decreased expression levels of the activating receptor NKp30 and impaired degranulation upon NKp30 cross-linking. Paradoxically, NK cells from patients with gastrointestinal stromal tumour produced more IFN $\gamma$ upon either IL- 2 stimulation or incubation with dendritic cells, the latter of which predicted improved response to imatinib mesylate treatment ${ }^{61}$. In NSCLC, transcript levels of activating receptors NCR1, NCR2 and NCR3 in peripheral NK cells are all decreased, reflecting impaired natural killer cell activation, and low NCR3 transcript expression and elevated serum levels of its ligand, B7-H6, were associated with poor survival ${ }^{62}$. In neuroblastoma, patients with metastatic disease exhibited lack of expression of the A and B isoforms of $\mathrm{NKp} 30$ in peripheral NK cells when compared with patients with localized disease and healthy individuals ${ }^{63}$. Conversely, another study in patients with NSCLC found that peripheral NK cells showed no phenotypic alterations by flow cytometry compared with cells from healthy individuals, but ex vivo incubation of these NK cells with tumour cells induced reduction of NK cell receptor expression and impaired degranulation compared with healthy donor-derived NK cells, suggesting that, in some contexts, NK cell perturbations are specific to the $\mathrm{TME}^{64}$.

Altogether, these data strongly support the notion that systemic corruption of immune organization occurs across diverse tumour types (FIG. 1; TABLE 1). Further work is needed to fully characterize the distinct types of immune states in patients with cancer and the associations of these types of immune states with the tumour tissue of origin, stage of development and patient demographics in order to inform therapeutic development and future mechanistic studies of the causes of systemic disruptions. It is also critical to understand why systemic immune changes are quite dramatic in some contexts yet subtle in others.

\section{Changes induced by conventional therapy}

Conventional therapeutic strategies in cancer, including chemotherapy, radiation and surgery, perturb the global immune landscape. Understanding these systemic immune consequences is important for designing strategies that augment rather than impede antitumour immune responses, which can include optimal timing, dosing or combinations.

Chemotherapy and radiation therapy remodel circulating immune populations. Chemotherapy and radiation therapy are designed to target cancer cells by compromising cellular integrity during division; however, these agents can also induce remodelling of immunity that can either impede or augment overall treatment efficacy. Consequences of conventional cancer therapies on the immune system were well reviewed by Shaked, such as expansion of immunosuppressive myeloid cells via elevated pro-inflammatory cytokines, including IL-6, IL-8 and GM-CSF, and B cell release of systemic extracellular vesicles that impede antitumour cytotoxic immune functions ${ }^{65}$. One counter-strategy is to pair these therapies with agents that block immunosuppressive phenotypes, such as inhibiting CSF1R or CCR2. Chemotherapeutic cytotoxicity also leads to general lymphodepletion, and although the numbers of $\mathrm{CD}^{+} \mathrm{T}$ cells in peripheral blood fully rebound to normal frequencies within a year, an abnormal bias of memory $\mathrm{CD}^{+} \mathrm{T}$ cells towards inflammatory effectors persists for years in patients with breast cancer ${ }^{66}$. Selecting agents that mitigate immune abnormalities may be optimal for enabling the strongest antitumour immune response.

The impact of chemotherapy and radiotherapy on the immune system depends highly on context, making it challenging but imperative to understand how each cytotoxic therapy may compromise immune function across cancer settings. In NSCLC, standard prolonged low-dose radiotherapy, but not chemotherapy, led to myeloid cell expansion, reduced antigen-presenting cell function and impaired $\mathrm{T}$ cell responses ${ }^{67}$. Similar immune impacts were observed after combination chemotherapy and radiotherapy in patients with cervical cancer ${ }^{68}$. Neoadjuvant chemotherapy prior to surgical resection is a strategy often used in breast cancer, but patients show disparate immune effects depending on the cancer stage and therapeutic agent. In patients with non-metastatic breast cancer, doxorubicin and cyclophosphamide chemotherapy led to elevated numbers of circulating PMN-MDSCs but no changes in M-MDSCs when compared with pretreatment numbers ${ }^{69}$. However, in patients with metastatic breast cancer treated with 5-fluorouracil (5-FU), epirubicin and cyclophosphamide (FEC) or docetaxel chemotherapies, M-MDSCs were dramatically reduced in six out of ten patients when compared with pretreatment levels ${ }^{70}$. Specifically, in patients with breast cancer with tumours expressing HER2 (HER2 ${ }^{+}$), a recent study suggests that higher circulating IL-10 and classical monocytes associate with reduced pathological complete responses after chemotherapy ${ }^{71}$. Future studies with larger numbers of patients and more complete measurements of the immune system are needed to 
Table 1 | Peripheral immune perturbations in cancer

\begin{tabular}{|c|c|c|c|}
\hline Immune cell type & Change & Tumour type and species ${ }^{a}$ & Refs \\
\hline \multirow[t]{2}{*}{$\begin{array}{l}\text { Haematopoietic stem } \\
\text { cells }\end{array}$} & \multirow[t]{2}{*}{ Increased frequency } & $\begin{array}{l}\text { Human: breast cancer, cervical cancer, liver cancer, } \\
\text { oesophageal cancer, lung cancer, ovarian cancer, } \\
\text { gastrointestinal cancer }\end{array}$ & \multirow[t]{2}{*}{$12,13,16,17$} \\
\hline & & Mouse: breast cancer ${ }^{\mathrm{M}}$, rhabdomyosarcoma ${ }^{\mathrm{M}}$ & \\
\hline \multirow[t]{2}{*}{$\begin{array}{l}\text { Multipotent } \\
\text { progenitor cells }\end{array}$} & \multirow[t]{2}{*}{ Increased frequency } & $\begin{array}{l}\text { Human: breast cancer, cervical cancer, liver cancer, } \\
\text { oesophageal cancer, lung cancer, ovarian cancer, } \\
\text { gastrointestinal cancer }\end{array}$ & \multirow[t]{2}{*}{$12,13,16,17$} \\
\hline & & Mouse: breast cancer ${ }^{\mathrm{M}}$, rhabdomyosarcoma ${ }^{\mathrm{M}}$ & \\
\hline \multirow[t]{2}{*}{$\begin{array}{l}\text { Granulocyte } \\
\text { monocyte } \\
\text { progenitors }\end{array}$} & \multirow[t]{2}{*}{ Increased frequency } & $\begin{array}{l}\text { Human: breast cancer, cervical cancer, liver cancer, } \\
\text { oesophageal cancer, lung cancer, ovarian cancer, } \\
\text { gastrointestinal cancer }\end{array}$ & \multirow[t]{2}{*}{$12,13,16,17$} \\
\hline & & Mouse: breast cancer ${ }^{\mathrm{M}}$, rhabdomyosarcoma ${ }^{\mathrm{M}}$ & \\
\hline \multirow{2}{*}{$\begin{array}{l}\text { Dendritic cell } \\
\text { precursors }\end{array}$} & \multirow[t]{2}{*}{ Decreased frequency } & Human: breast cancer ${ }^{\mathrm{NM}}$, pancreatic cancer & \multirow[t]{2}{*}{18} \\
\hline & & Mouse: breast cancer, pancreatic cancer & \\
\hline \multirow[t]{2}{*}{$\begin{array}{l}\text { Immature } \\
\text { neutrophils/ } \\
\text { PMN-MDSCs }\end{array}$} & \multirow[t]{2}{*}{ Increased frequency } & $\begin{array}{l}\text { Human: breast cancer, pancreatic cancer, lung } \\
\text { cancer }^{\mathrm{M} / \mathrm{NM}} \text {, bladder cancer }{ }^{\mathrm{M} / \mathrm{MM}} \text {, head and neck } \\
\text { cancer }^{\mathrm{M} / \mathrm{NM}} \text {, glioblastoma, melanoma }\end{array}$ & \multirow[t]{2}{*}{$\begin{array}{r}11,12,18, \\
28,160-163\end{array}$} \\
\hline & & $\begin{array}{l}\text { Mouse: breast cancer }{ }^{\mathrm{M}} \text {, melanoma }{ }^{\mathrm{M}} \text {, pancreatic cancer }{ }^{\mathrm{M}} \text {, } \\
\text { colon cancer }^{\mathrm{NM}} \text {, glioblastoma }\end{array}$ & \\
\hline \multirow[t]{2}{*}{$\begin{array}{l}\text { Immature } \\
\text { monocytes/M-MDSCs }\end{array}$} & \multirow[t]{2}{*}{ Increased frequency } & $\begin{array}{l}\text { Human: renal cell carcinoma, prostate cancer, prostate } \\
\text { cancer, melanoma }{ }^{\mathrm{M} / \mathrm{NM}} \text {, hepatocellular carcinoma }\end{array}$ & \multirow[t]{2}{*}{$\begin{array}{r}14,22,28 \\
164-167\end{array}$} \\
\hline & & $\begin{array}{l}\text { Mouse: breast cancer } r^{\mathrm{M} / \mathrm{NM}}, \text { melanoma }{ }^{\mathrm{M}} \text {, pancreatic } \\
\text { cancer }^{\mathrm{M}} \text {, colon } \text { cancer }^{\mathrm{NM}} \text {, glioblastoma }\end{array}$ & \\
\hline \multirow[t]{2}{*}{ Dendritic cells } & \multirow[t]{2}{*}{ Decreased frequency } & $\begin{array}{l}\text { Human: ovarian cancer, prostate cancer, breast cancer, } \\
\text { head and neck squamous cell carcinoma, melanoma }{ }^{\mathrm{M} / \mathrm{NM}} \text {, } \\
\text { lung cancer }{ }^{\mathrm{NM}} \text {, renal cancer }\end{array}$ & \multirow[t]{2}{*}{$\begin{array}{r}11,18,28, \\
32-34,36,168\end{array}$} \\
\hline & & $\begin{array}{l}\text { Mouse: pancreatic cancer }{ }^{\mathrm{M}} \text {, breast cancer }{ }^{\mathrm{M} / \mathrm{NM}} \text {, } \\
\text { glioblastoma }\end{array}$ & \\
\hline T cells & Decreased TCR repertoire & Human: breast cancer $^{\mathrm{M}}$, lung cancer ${ }^{\mathrm{M} / \mathrm{NM}}$, cervical cancer & 43-45 \\
\hline \multirow[t]{2}{*}{$\mathrm{T}_{\text {reg }}$ cells } & \multirow[t]{2}{*}{ Expansion } & $\begin{array}{l}\text { Human: lung cancer }{ }^{\mathrm{M} / \mathrm{NM}} \text {, prostate cancer }{ }^{\mathrm{NM}} \text {, gastric } \\
\text { cancer }^{\mathrm{M} / \mathrm{NM}} \text {, colorectal cancer, oesophageal cancer, } \\
\text { hepatocellular carcinoma, pancreatic cancer, breast } \\
\text { cancer }^{\mathrm{NM}}\end{array}$ & \multirow[t]{2}{*}{$\begin{array}{r}28,51, \\
169-174\end{array}$} \\
\hline & & Mouse: melanoma, pancreatic cancer & \\
\hline $\mathrm{T}_{\text {reg }}$ cells & Clonal expansion & $\begin{array}{l}\text { Human: melanoma }{ }^{\mathrm{M}} \text {, gastrointestinal cancer, ovarian } \\
\text { cancer, breast cancer }\end{array}$ & 52,53 \\
\hline \multirow[t]{2}{*}{ Regulatory B cells } & \multirow[t]{2}{*}{ Increased frequency } & Human: gastric cancer $\mathrm{M} / \mathrm{NM}$, lung cancer & \multirow[t]{2}{*}{$55-57$} \\
\hline & & Mouse: breast cancer ${ }^{\mathrm{M}}$ & \\
\hline $\begin{array}{l}\mathrm{CD}^{+} \text {and } \mathrm{CD} 8^{+} \\
\text {T cells }\end{array}$ & $\begin{array}{l}\text { Decreased IL-2 and IFN } \gamma \\
\text { production after PMA and } \\
\text { ionomycin stimulation }\end{array}$ & Human: breast cancer ${ }^{\mathrm{M} / \mathrm{NM}}$ & 49 \\
\hline $\mathrm{CD}^{+}{ }^{+} \mathrm{T}$ cells & $\begin{array}{l}\text { Decreased pSTAT1 and } \\
\text { pSTAT3 signalling after } \\
\text { IL-6 stimulation }\end{array}$ & Human: breast cancer & 50 \\
\hline Natural killer cells & $\begin{array}{l}\text { Decreased activating } \\
\text { receptors, increased } \\
\text { inhibitory receptors, } \\
\text { decreased cytotoxic } \\
\text { potential }\end{array}$ & $\begin{array}{l}\text { Human: breast cancer }{ }^{\mathrm{M} / \mathrm{NM}} \text {, lung } \text { cancer }^{\mathrm{NM}} \text {, } \\
\text { gastrointestinal cancer }^{\mathrm{M} / \mathrm{NM}} \text {, neuroblastoma }\end{array}$ & 60-64 \\
\hline
\end{tabular}

M-MDSC mononuclear myeloid-derived suppressor cell; PMN-MDSC, polymorphonuclear myeloid-derived suppressor cell; TCR, $T$ cell receptor; $\mathrm{T}_{\text {reg }}$ cell, regulatory $\mathrm{T}$ cell. ${ }^{a}$ Superscript ${ }^{\mathrm{M}}$ indicates that this observation was specifically made in metastatic disease, whereas ${ }^{\mathrm{NM}}$ indicates that the observation was specifically made in non-metastatic disease.

parse how the disease type and stage affect the immune consequences of cytotoxic therapies.

When demonstrably effective, chemotherapy can augment systemic antitumour immunity in conjunction with disrupting cancer cell division. Recent work showed that effective responses to pre-surgical neoadjuvant chemotherapy in triple-negative breast cancer (TNBC) induces the recruitment of new T cell clones to the TME rather than expanding those already present $^{72}$. Importantly, different subtypes of breast cancer showed differential immune responses to this therapeutic strategy, reflected in the functionality of peripheral 
$\mathrm{CD}^{+} \mathrm{T}$ cells. Patients with oestrogen receptor-positive $\left(\mathrm{ER}^{+}\right)$breast tumours had a drop or stasis in the polyfunctionality of circulating $\mathrm{PD} 1^{+} \mathrm{CD}^{+} \mathrm{T}$ cells, measured by cytokine production after TCR stimulation. Patients with ER ${ }^{+} \mathrm{HER} 2^{+}$breast tumours showed a complete loss of functionality in this subset. Conversely, patients with TNBC showed elevated $\mathrm{PD} 1^{+} \mathrm{CD} 8^{+} \mathrm{T}$ cells with high functionality, producing effector cytokines including IFN $\gamma$ and TNF, and the cytolytic molecule granzyme $\mathrm{B}$, and with evidence of clonal expansion. Ultimately, tumour-infiltrating $\mathrm{T}$ cells were only prognostic for overall survival in TNBC. Moreover, a cytolytic but exhausted $\mathrm{CD} 8^{+} \mathrm{T}$ cell signature in the blood of patients with TNBC following chemotherapy was associated with ongoing disease and was predictive of recurrence or metastasis post surgery.

With the advent of immunotherapy, therapeutic strategies are shifting towards utilizing cytotoxic therapeutic agents that can augment antitumour immunity, such as by disrupting the tumour stroma or by releasing tumour antigens for de novo activation of the adaptive immune system ${ }^{73-75}$.

Tumour resection can impact immunological control of cancer. Recent studies have provided a deeper understanding of the impact of surgical tumour resection on the systemic immune state and immunological control of metastases. Metastatic outgrowth following surgical tumour resection has been documented in several cancer types, where a wide range of pro-tumorigenic processes, including shedding of tumour cells into circulation and stimulation of angiogenesis, lead to new and accelerated metastatic growth despite resection of the primary tumour $^{76}$. For the purposes of this Review, we focus on alterations to antitumour immunity following surgery (other aspects driving postoperative metastasis are reviewed elsewhere ${ }^{77}$ ). Several recent studies implicate myeloid immune cell remodelling induced by systemic wound healing programmes. Resection, or wounding independent of primary tumour removal, triggers healing programmes that elevate circulating IL-6, G-CSF and CCL2, and ultimately drive myeloid subsets towards immunosuppressive states ${ }^{78}$. Although resection substantially reduces the number of systemic MDSCs in the spleen, blood and lung in the 4T1 breast cancer model, functional immunosuppressive PMN-MDSCs can persist in these peripheral tissues for 2 weeks ${ }^{79}$. Persistent immunosuppressive myeloid cells were shown to support pro-tumorigenic niches in the lungs in both breast cancer and osteosarcoma models ${ }^{79,80}$. Mechanistically, one study showed that neutrophil extracellular traps increased in the liver following surgical intervention and ensnared tumour cells to promote metastasis ${ }^{77}$. Modulation of myeloid subsets in the adjuvant setting can prevent post-surgical metastases, including the use of gemcitabine to deplete PMN-MDSCs ${ }^{79}$ or gefitinib to alter inflammatory macrophage states by blocking signalling through receptor-interacting protein kinase 2 $(\text { RIPK2 })^{80}$. Surgical procedures in a mouse tumour vaccination model showed that tumour-specific $T$ cell responses were dramatically weakened for 7-10 days following surgery ${ }^{81}$. Similarly, a mouse model of surgical stress, in which mice underwent an abdominal laparotomy and left nephrectomy, showed that surgery led to decreased systemic NK cell frequencies and tumour killing potential, which culminated in impaired control of lung metastasis ${ }^{82}$. Patients with colorectal cancer also exhibited decreased IFN $\gamma$ secretion from peripheral NK cells when compared with healthy individuals, and this was further decreased for up to 2 months following surgery ${ }^{83}$. Collectively, these data suggest multiple mechanisms by which surgical resection induces global immunological perturbations that can promote metastasis.

However, our group recently demonstrated that the primary tumour can be the main driver of systemic immune remodelling: successful primary tumour resection in mouse models of breast and colon cancer was sufficient to largely restore normal systemic immune organization to immune cell frequencies comparable with healthy control mice across the spleen, lymph node, blood and bone marrow given that there was sufficient time to recover from postoperative complications ${ }^{28}$. In the highly metastatic 4T1 mouse model, lung metastatic outgrowth was observed in some animals following surgery and yet only minor systemic immune changes were maintained. Furthermore, we and others found that surgical tumour resection in mice ultimately restored functional orthogonal responses to infection, vaccination or allogeneic tumour challenges ${ }^{28,84}$. Therefore, it is likely that surgery results in both detrimental and beneficial effects on the systemic immune system. Immunosuppressive mechanisms coinciding with wound healing early after surgery potentially provide a window of opportunity for disseminated cancer cells to grow out. However, the reduced primary tumour burden can ultimately restore systemic immune capacity for strong adaptive responses. It will be important to discover how the cancer type and, particularly, disease stage influence immune remodelling following surgery and the resulting potential for metastasis.

Appropriate pairing of conventional therapies with immune modulation can be a powerful tool to combat cancer, and taking the systemic immune context into account is likely to result in improved outcomes. It is particularly important to consider the immunologically vulnerable period of time following surgery and further investigate the mechanisms driving these states as well as potential therapeutic interventions to restore immune function and prevent tumour recurrence and metastasis.

\section{Systemic responses in immunotherapy}

Cancer immunotherapy has radically expanded our toolkit against cancer, with current US Food and Drug Administration (FDA) approval of 7 ICIs across 19 different cancer types, in addition to chimeric antigen receptor $\mathrm{T}$ cells, bispecific $\mathrm{T}$ cell engager (BiTE) therapies and vaccines. The prevailing view of cancer immunotherapy efficacy has centred around the notion of reinvigorating cytotoxic effectors within the TME, but appreciation is growing in the field for the fundamentally systemic nature of effective antitumour immunity. Recent studies demonstrate that ICIs, including blockade of the PD1 and PDL1 axis, rely on systemic immune 


\section{Box 1 | Microbiome modulation of systemic immunity in cancer}

The activity and composition of the microbiome influences the organization of the human immune system ${ }^{175}$. Antibiotic treatment that disrupts the gut microbiome leads to resistance to immune checkpoint inhibitors (ICls) in mouse models of cancer and in patients with cancer ${ }^{176}$. Multiple studies have found that faecal microbiota transplantation (FMT) from patients into mouse models can recapitulate functional outcomes on tumour control and response to $\mathrm{ICl}$ s such that $\mathrm{FMT}$ from $\mathrm{ICl}$ responders drives improved antitumour immune responses compared with $\mathrm{FMT}$ from $\mathrm{ICl}$ nonresponders $^{176-180}$. In fact, FMT from ICI non-responders compared with responders drove divergent peripheral immune responses, such as higher frequencies of regulatory CD4 T cells and Thelper 17 cells in the spleen of non-responder FMT recipients, suggesting systemic consequences of microbiome composition in patients with cancer ${ }^{177}$. Although much mechanistic work is still needed to link microbiome to immune composition and function, Bifidobacterium pseudolongum and Akkermansia muciniphila have been shown to produce inosine that activates antitumour T cells via the adenoside $A_{2 A}$ receptor ${ }^{179}$. One study identified an 11-strain mixture of commensal bacteria that enhances antitumour immune responses through $\mathrm{CD} 103^{+}$dendritic cell-orchestrated $\mathrm{CD} 8^{+} \mathrm{T}$ cell responses. Systemically, the same 11-strain mixture also drove enhanced intestinal bacterial clearance following oral Listeria monocytogenes infection as well as improved spleen and liver bacterial clearance after intraperitoneal L. monocytogenes infection ${ }^{180}$. These data suggest that microbiome-based improvements of antitumour immunity also shape systemic immunity. This topic has been reviewed in greater depth elsewhere ${ }^{181}$.

mechanisms to achieve effective antitumour responses. Furthermore, the microbiome is emerging as a potent modulator of the immune system, and the relevant impact on antitumour immune responses is discussed in BOX 1.

Intact peripheral immunity is critical for immunotherapeutic efficacy. Intact peripheral immune function, communication and trafficking are required for ICI efficacy. Disruption of peripheral immune integrity by systemic chemotherapy can impede therapeutic benefit by PD1 blockade, causing systemic lymphodepletion and abrogating long-term immune memory ${ }^{85}$. By contrast, local chemotherapy spares peripheral immunity, collaborating with PD1 blockade to induce dendritic cell infiltration into the tumour and clonal expansion of antigen-specific effector T cells ${ }^{85}$. A specialized subset of $\mathrm{CD} 103^{+}$dendritic cells transport tumour antigen to the peripheral immune system by CCR7-dependent migration from the tumour to the $\mathrm{dLN}$, where the priming of tumour-specific $\mathrm{CD}^{+}$and $\mathrm{CD} 4^{+} \mathrm{T}$ cells occurs $^{86-89}$ (FIG. 2). cDC2s are also capable of trafficking tumour antigen to the $\mathrm{dLN}$ and priming tumour-specific $\mathrm{CD}^{+}$and $\mathrm{CD}^{+} \mathrm{T}$ cells; however, this process is often restrained by intratumoural $\mathrm{T}_{\text {reg }}$ cells $\mathrm{s}^{30,90}$. Recent evidence suggested that dendritic cells migrating from the tumour to the dLN can transfer antigen to lymph node-resident dendritic cells that can then also prime tumour-specific T cells $^{90}$ (FIG. 2). Newly primed tumour-specific T cells then traffic from the lymph node to the tumour, and this cycle is an essential process in natural and therapeutically induced antitumour immunity ${ }^{91}$. As further evidence of the systemic nature of antitumour immunity, blockade of lymphocyte egress from lymphoid organs or surgical resection of tumour dLNs abrogates immunotherapeutic efficacy ${ }^{92,93}$. The eradication of systemic disease also heavily relies on global immune responses. Strong adaptive immune responses confer peripheral memory, where the transfer of $\mathrm{T}$ cells from secondary lymphoid organs (including the spleen, lymph node and blood) after productive antitumour responses is sufficient to protect naive animals ${ }^{92}$. This same study showed that systemic PDL1 blockade can break tolerance to disseminated tumours when paired with local therapeutic delivery at one site.

It has become clear that inhibiting the PD1-PDL1 axis has impacts beyond blocking local immunosuppressive cues in the tumour, and recent work has clarified key peripheral immune cells driving responses in these settings. First, therapeutic benefit of immune checkpoint inhibition is only observed in models with intact host PD1 and PDL1 expression and is less dependent on cancer cell expression of PDL1 (REFS ${ }^{94-96}$ ). Aside from tumour cells, the majority of cells that express PDL1 are antigen-presenting cells, including macrophages and, at even higher levels, $\mathrm{cDCs}^{97}$. In patients with melanoma or ovarian cancer, expression levels of PDL1 on intratumoural macrophages and CDCs correlate with clinical complete responses to anti-PDL1 and anti-CTLA4 therapy ${ }^{95}$. Moreover, several groups have recently demonstrated that dendritic cells are a critical mediator of PDL1 blockade efficacy ${ }^{97-100}$. Targeted depletion of PDL1 in cDCs, but not macrophages, substantially reduced $\mathrm{CD}^{+} \mathrm{T}$ cell responses and tumour shrinkage in response to PDL1 blockade in the subcutaneous MC38 mouse cancer model ${ }^{97}$. The critical location for this interaction appears to be the tumour dLNs, as tumour-specific $\mathrm{PD}^{+} \mathrm{T}$ cells in the $\mathrm{dLN}$ showed high co-localization with PDL1-expressing $\mathrm{CDCs}^{98}$. Selective targeting of PDL1 engagement in the dLNs was sufficient to induce effective antitumour responses across two syngeneic models, albeit to a lesser extent than systemic PDL1 blockade ${ }^{98}$. Further supporting the significance of PDL1 activity specifically on cDCs, interactions between $\mathrm{PDL}^{+}{ }^{+} \mathrm{CDCs}$ and $\mathrm{PD} 1^{+} \mathrm{T}$ cells in $\mathrm{dLN}$ were indicative of the disease dissemination status in patients with melanoma. Frequent PD1 and PDL1 interactions in dLNs were observed in patients with metastatic melanoma and were predictive of early disseminated disease recurrence in patients with non-metastatic melanoma ${ }^{98}$. Augmenting effector and memory $\mathrm{T}$ cell development in the dLN via mitochondrial activation further improved PD1 blockade efficacy in tumour-bearing mice ${ }^{101}$, again highlighting that systemically engaged immunity is clearly optimal for tumour eradication.

\section{Effective immunotherapies drive de novo immune} responses. Productive antitumour responses ultimately necessitate functional effector lymphocytes within the TME to mediate cancer cell killing. However, recent studies revealed that intratumoural $\mathrm{T}$ cells acquire terminally exhausted states over time, rendering them incapable of key effector functions (FIG. 2). Analysis of epigenetic landscapes of $\mathrm{CD} 8^{+} \mathrm{T}$ cells in mice and patients with cancer showed that intratumoural $\mathrm{T}$ cells underwent extensive chromatin remodelling, which locked cells in dysfunctional states and reduced the ability of these cells to produce TNF and IFN $\gamma^{102}$. This process was biphasic in preclinical models, where early T cell remodelling was reversible upon removal from the tumour context, but a second wave of epigenetic remodelling led to irrecoverable $\mathrm{T}$ cell dysfunction marked by 
a Baseline treatment-naive tumour

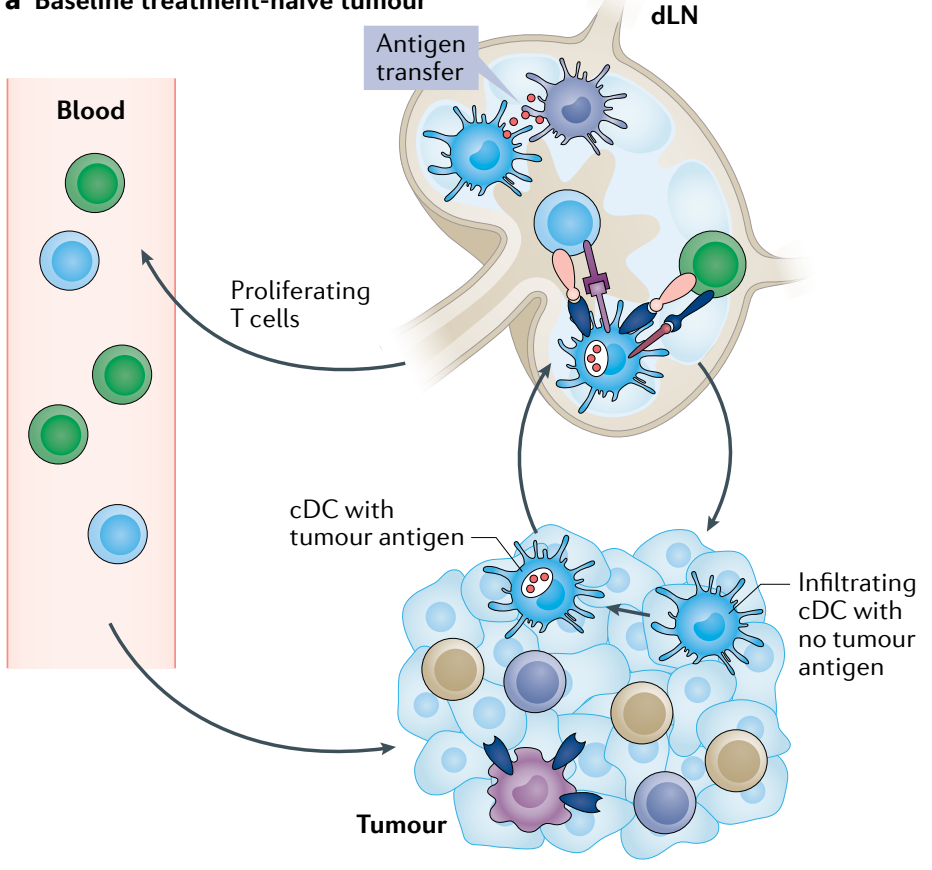

b After anti-PDL1 or anti-CD40 immunotherapy

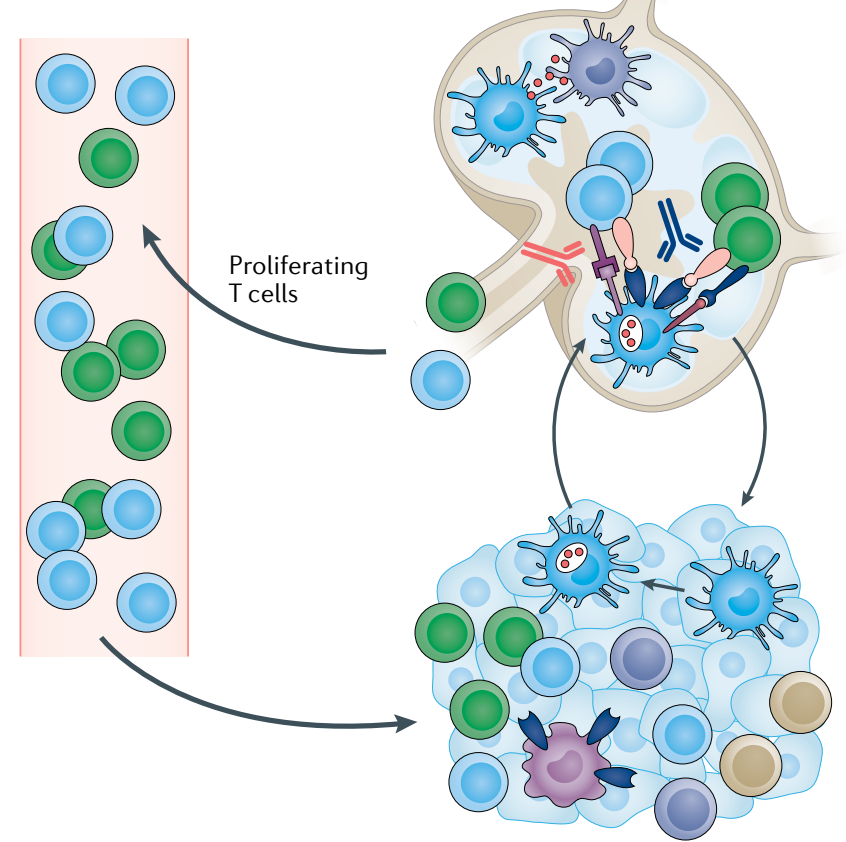

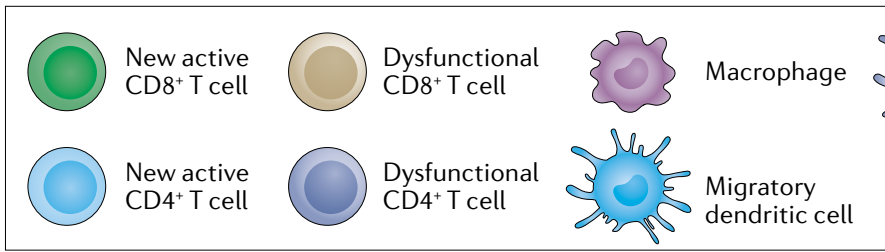

Fig. 2 | Systemic immune responses in cancer immunotherapy. Effective responses to immunotherapy drive de novo peripheral immune responses. Schematic illustrating how functional antitumour responses are reliant on immune dynamics outside the tumour microenvironment (TME). a | At baseline, conventional dendritic cells (cDCs) in the TME take up tumour antigen and travel to the draining lymph node ( $d L N)$, where they can then transfer antigen to resident cDCs through the formation of direct synapses. $T$ cells in the TME reach states of terminal exhaustion due to chronic stimulation, the harsh environment and immunosuppressive cues. Dysfunctional intratumoural T cells accumulate structurally damaged mitochondria, and upregulate CD103 and CD38 coinciding with irreversible epigenetic remodelling. Thus, effective antitumour responses driven by

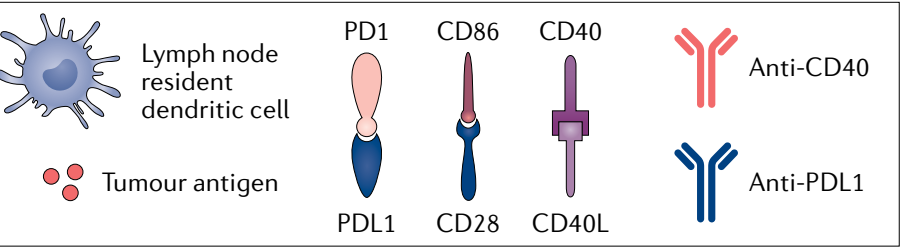

therapy must rely on another source of functional effector T cells. b | Immunotherapeutic intervention through PD1 and PDL1 checkpoint blockade increases the interaction between $\mathrm{cDCs}$ and naive T cells in the $\mathrm{dLN}$, and, alongside CD28 co-stimulation, facilitates the priming and rapid expansion of new T cell clones with new antigen specificities. Checkpoint blockade also leads to the proliferation of existing $T$ cell clones in circulation. These expanding peripheral T cells ultimately infiltrate the TME, and express markers indicative of antigen-specific activation and demonstrate functional cytotoxicity. Productive de novo immune responses can also be achieved through CD40 agonism, which can drive cDC activation in settings resistant to checkpoint blockade and initiate these new $T$ cell responses to replace exhausted intratumoural clones.
T cell exhaustion A terminal state of $\mathrm{T}$ cell differentiation driven by chronic T cell receptor (TCR) stimulation and characterized by expression of inhibitory receptors and hypofunctionality, including a reduced capacity to secrete cytokines.
CD101 and CD38 co-expression ${ }^{102}$. Additional studies have identified the transcription factor TOX as a critical regulator in transcriptional and epigenetic reprogramming in response to chronic $\mathrm{T}$ cell stimulation, leading to $\mathrm{T}$ cell exhaustion ${ }^{103,104}$. This intratumoural $\mathrm{T}$ cell dysfunction is driven by microenvironmental stressors in the TME, chronic TCR stimulation and checkpoint protein signalling ${ }^{103-106}$. A study recently showed that metabolic challenges within the tumour can cause T cells to accumulate structurally damaged mitochondria with high levels of reactive oxygen species and overall compromised membrane potential ${ }^{105}$. Importantly, mitochondrial dysregulation was sufficient to induce epigenetic reprogramming towards terminal dysfunction and was not observed in peripheral $\mathrm{T}$ cells from the spleen or dLN. Clinical responses to ICIs in patients with melanoma were associated with the presence of a stem-like $\mathrm{CD}^{+} \mathrm{T}$ cell state with reduced expression of co-inhibitory molecules and elevated memory, activation and cell survival transcriptional and epigenetic programmes compared with exhausted CD8 ${ }^{+} \mathrm{T}$ cells ${ }^{107}$. These productive intratumoural $\mathrm{CD}^{+} \mathrm{T}$ cells can be identified by expression of the transcription factor TCF1 (which is involved in WNT signalling in stem cell-like memory programmes) and notable lack of expression of CD39 and TIM3 (REF. ${ }^{107}$ ). Thus, immunotherapy efficacy relies on the quality of effector $\mathrm{CD}^{+} \mathrm{T}$ cells within the TME, but persistence in this toxic microenvironment rapidly drives dysfunctional differentiation of $\mathrm{T}$ cells that lose their ability to efficiently contribute to tumour clearance.

To overcome local immune dysfunction, effective immunotherapies drive de novo peripheral immune responses culminating in new effector $\mathrm{T}$ cell infiltration (FIG. 2). Several reports have now shown that PD1 and PDL1 blockade drive novel T cell clones into the TME that were not present locally prior to therapy ${ }^{108-110}$. In a recent study in patients with basal cell carcinoma 
before and after PD1 blockade, $68 \%$ of all intratumoural $\mathrm{CD}^{+} \mathrm{T}$ cell clones after PD1 blockade were novel, $84 \%$ of which displayed exhaustion markers indicative of antigen-specific activation, and these cells represented novel TCR specificity groups, suggesting priming against new antigen targets ${ }^{108}$. Further, $35.5 \%$ of these novel clones were also detected in the blood, with $11.8 \%$ detected in circulation pretreatment. Correlation between $\mathrm{T}$ cell clones in the blood and tumour was also demonstrated in patients with metastatic melanoma, renal cancer, lung cancer and colon cancer ${ }^{109,110}$. Anti-CTLA4 has also been shown to dramatically increase peripheral $\mathrm{T}$ cell reactivities in patients with melanoma, suggesting new $\mathrm{T}$ cell priming as a mechanism of action ${ }^{111}$.

Mechanistically, cell-intrinsic CD28 signalling in $\mathrm{CD}^{+} \mathrm{T}$ cells is critical in PD1 blockade efficacy ${ }^{112,113}$, providing necessary co-stimulation for naive $\mathrm{T}$ cell priming. In line with this finding, a higher baseline proportion of $\mathrm{CD} 28^{-} \mathrm{CD} 57^{+} \mathrm{KLRG} 1^{+}$senescent $\mathrm{CD} 8^{+}$ $\mathrm{T}$ cells in the blood of patients with NSCLC was associated with resistance to ICIs ${ }^{114}$. Impressively, in patients with classical Hodgkin lymphoma, the peripheral $\mathrm{T}$ cell clonal diversity at baseline was associated with PD1 blockade efficacy, illustrating how individual systemic immune contexts dictate the impact of immunotherapeutic intervention ${ }^{115}$. This signature was complemented by greater expansion of singleton clones in the blood of patients with complete response, likely representing peripheral $\mathrm{T}$ cells that had not encountered antigen pretreatment. The antitumour immune response in this cancer context was more reliant on $\mathrm{CD} 4^{+} \mathrm{T}$ cells, with expanded CD4 ${ }^{+}$TCR diversity, and concordant associations with circulating B cell abundance and a novel innate effector population capable of antibody-dependent cellular cytotoxicity. Together, these results support the notion that not only is peripheral immunity involved in renewed antitumour responses but also de novo priming of additional naive $\mathrm{T}$ cells with new antigen specificities contributes to effective immunotherapy (FIG. 2).

Intentional strategies for driving de novo immune responses are gaining traction in clinical trials, including stimulation of dendritic cell activity through various strategies such as agonistic CD40 antibodies ${ }^{116,117}$. Several studies have demonstrated that immune checkpoint blockade relies on derestricting cDCs to allow for effective $\mathrm{T}$ cell priming ${ }^{97-100}$, but this strategy fails in cases where there is a poor or absent pre-existing activation of antigen-presenting cells. Patients with pancreatic cancer are resistant to ICIs, but preclinical models demonstrate that combination with CD40 agonism can produce complete pancreatic tumour regression and extend survival independent of TLR, STING or IFNAR signalling ${ }^{118}$. Efficacy in this particular $\mathrm{Kras}^{L S L-G 12 D /+}, \operatorname{Tr} p 53^{L S L-R 172 H /+}, P d x 1-$ Cre model was dependent on host BATF3 ${ }^{+}$cDC1s and CD40, as well as effector $\mathrm{CD}^{+}$and $\mathrm{CD} 8^{+} \mathrm{T}$ cells, which massively expanded in the blood and dLNs, indicative of peripheral immune activation ${ }^{118}$. An early clinical trial in patients with metastatic pancreatic cancer holds promise, where combination of CD40 agonism with PD1 blockade and gemcitabine and nab-paclitaxel chemotherapy shows a greater than $50 \%$ objective response rate and the induction of proliferating $\mathrm{CD} 4^{+}$and $\mathrm{CD} 8^{+} \mathrm{T}$ cells in the blood ${ }^{119}$. CD40 activation is just one strategy demonstrating that converting immunologically 'cold' tumour contexts into 'hot' immune involvement requires de novo immune responses rather than reinvigoration.

\section{Secondary immune challenges in cancer}

The prior experience and state of the immune system dramatically shapes future responses to new challenges. Altered basal cytokine levels, cellular composition and cellular activation states are known to impact the nature and magnitude of secondary responses in models of chronic infection and co-infection ${ }^{120-122}$. As the systemic immune state is significantly reorganized in individuals bearing tumours, this may have functional consequences on the orchestration of new immune responses. Identifying systemic functional deficits to immunological challenges, such as vaccines or infections, in patients with cancer remains challenging due to the effects of common cancer therapies. Patients with cancer are capable of developing detectable antibodies in response to influenza vaccination that are comparable with healthy individuals ${ }^{123}$. However, during the ongoing 2020 SARS-CoV-2 pandemic, patients with cancer who are infected with SARS-CoV-2 are more likely to develop severe symptoms and exhibit higher mortality rates $^{124,125}$. Notably, even infected patients not receiving cancer treatment were at increased risk of mortality and severe illness ${ }^{125}$. This observation suggests that the substantial phenotypic and compositional changes to the systemic immune system across many cell types could lead to altered immune responses to a secondary challenge outside the TME. As an intact functional peripheral immune system is critical for the development of new antitumour immune responses, as described in the previous section, it is imperative to understand how immunological decisions are made within the context of a tumour-burdened state.

Recent work has begun to mechanistically dissect why the tumour-burdened immune state results in weakened peripheral secondary immune responses by investigating the effects of immune challenges that share no antigens with the initial tumour. By utilizing preclinical mouse model systems, the many confounding factors that impact studies in patients are avoided. It has been reported that of breast tumour-bearing mice mounted weaker antibody responses and $\mathrm{T}$ cell proliferation in response to an immunization challenge as well as showed impaired rejection of an allogeneic tumour ${ }^{84}$ (FIG. 3a). Similarly, our group showed that mice with AT3 breast tumours infected with Listeria monocytogenes mounted diminished splenic antibacterial responses marked by decreased dendritic cell expression of CD86, CD80 and CD83 at 2 days post infection ${ }^{28}$ (FIG. 3b). This ultimately led to reduced $\mathrm{CD}^{+} \mathrm{T}$ cell proliferation and differentiation at 7 days post infection compared with healthy control mice infected with $L$. monocytogenes, which could be rescued by CD40 agonist treatment or surgical resection of the tumour (FIG. 3b). Strikingly, surgical tumour resection also restored humoral and cellular responses to immunization ${ }^{84}$. Similarly, the splenic $\mathrm{CD}^{+}$ 


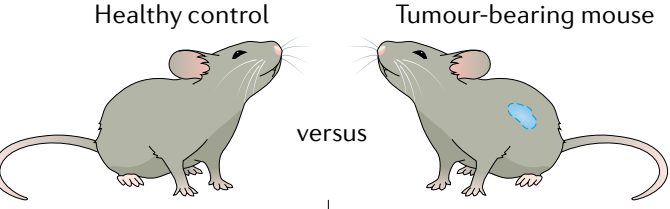

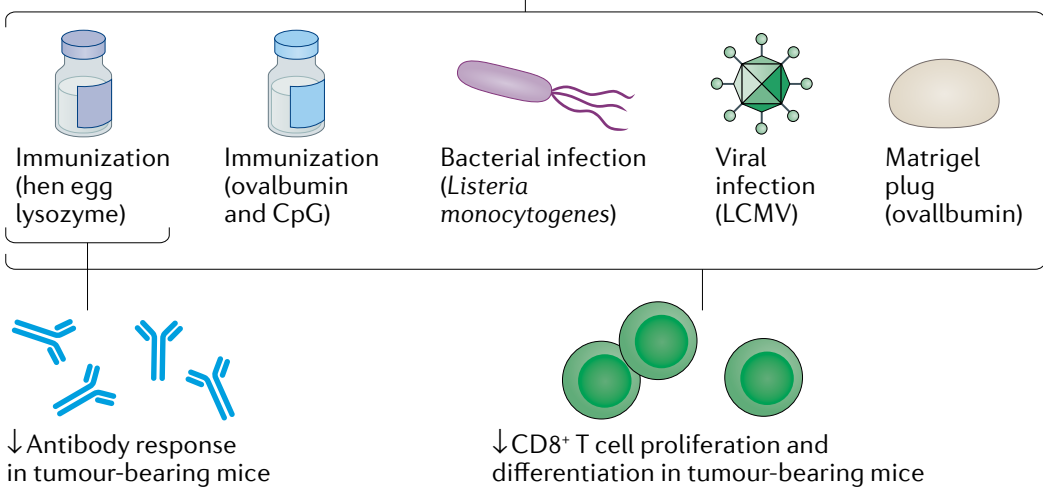

b Systemic CDC function

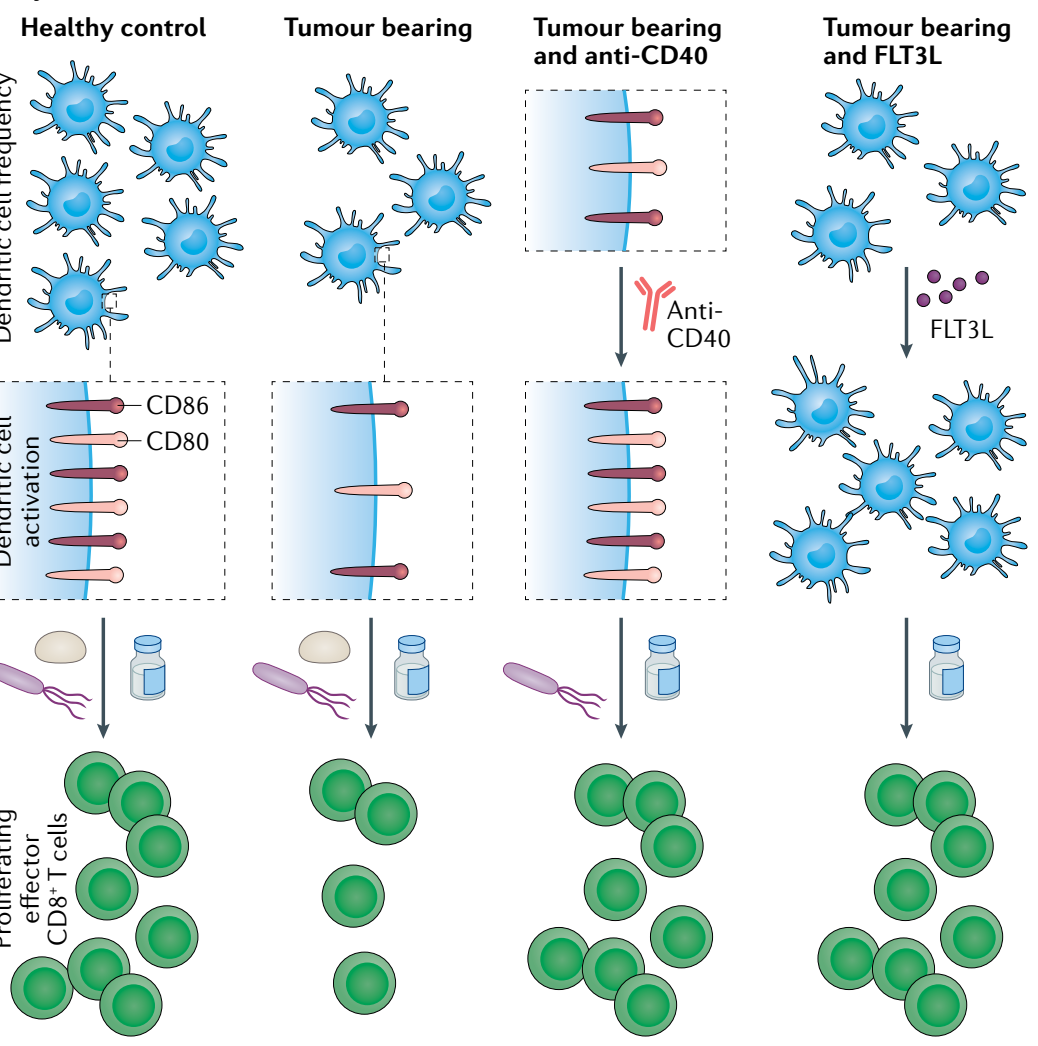

Fig. 3 | Secondary immune challenges in the context of cancer. Orthogonal challenges that do not share antigens with the tumour and drive immune responses away from the tumour microenvironment have revealed functional impairments in tumour-burdened hosts. a | Various challenges in tumour-bearing mice, including immunizations, bacterial and viral infections, and a Matrigel plug containing a new antigen not expressed in the tumour have shown blunted CD8 ${ }^{+} \mathrm{T}$ cell proliferation and differentiation. An impaired antibody response has also been observed in response to immunization. $\mathbf{b}$ | Mechanistically, several of these challenges (immunization, bacterial infection and Matrigel plug) have been linked to systemic dendritic cell paucity or impaired activation, described in the draining lymph node (dLN) and spleen. The precise drivers of dendritic cell impairment in cancer are still being investigated, but they involve altered dendritic cell development and apoptosis induced by increased circulating IL-6. Immunotherapeutic interventions that activate dendritic cells (anti-CD40) or increase their abundance (FLT3L) have restored $C D 8^{+} T$ cell proliferation and differentiation. $C D C$, conventional dendritic cell; LCMV, lymphocytic choriomeningitis virus.
T cell response to L. monocytogenes in Pan02 pancreatic tumour-bearing mice also showed perturbed $\mathrm{T}$ cell differentiation characterized by the acquisition of an exhausted fate ${ }^{126}$. Suppressed splenic expansion of $\mathrm{CD} 8^{+}$ $\mathrm{T}$ cells has also been observed in response to lymphocytic choriomeningitis virus in mice with pre-existing B16 melanoma ${ }^{127}$ or AT3 breast tumours ${ }^{28}$ when compared with healthy control infected mice. Vaccination of pancreatic tumour-bearing mice with ovalbumin (OVA) and $\mathrm{CpG}$ also led to impaired OVA-specific $\mathrm{CD}{ }^{+} \mathrm{T}$ cell proliferation and differentiation in the spleen when compared with healthy control vaccinated mice ${ }^{39}$. This impairment was linked to dendritic cell dysfunction and could be rescued by combined treatment with FLT3L and CD40 agonism to increase both dendritic cell numbers and activation, respectively ${ }^{39}$ (FIG. 3b). In a PyMT-B6 mouse model of breast cancer, a Matrigel plug containing poly I:C and OVA was used as an immunogenic secondary challenge without shared antigens to the primary tumour. Pre-existing malignancy drove significantly decreased frequency of $\mathrm{CDC} 1 \mathrm{~s}$ within the plug and the dLN, which then led to a reduced number of OVA-specific $\mathrm{CD}^{+} \mathrm{T}$ cells infiltrating the plug when compared with healthy control challenged mice ${ }^{18}$. Taken together, the results of these studies show that the innate and adaptive arms of immune responses, and specifically dendritic cell and $\mathrm{CD} 8^{+} \mathrm{T}$ cell interactions, do not proceed optimally in the context of cancer (FIG. 3). Thus, therapeutic strategies aiming to stimulate new $\mathrm{CD} 8^{+}$ $\mathrm{T}$ cell responses must overcome these obstacles.

\section{Systemic immune biomarkers for cancer}

Despite significant interest in the development of predictive biomarkers leveraging the systemic immune system, the vast majority of immunotherapy clinical trials are still performed without the use of a biomarker to guide inclusion ${ }^{128}$. Currently, there is no systemic immune biomarker that is sufficiently established to permit bedside decision-making, although some immunological features in the TME have been shown to be associated with prognosis in various contexts. Therefore, an opportunity exists for immune biomarkers from peripheral blood to help guide patient treatment decisions.

Circulating protein biomarkers. Quantification of circulating proteins in the serum or plasma is routinely performed in various pathological contexts, and thus several studies have examined the potential of this approach to develop predictive biomarkers for cancer therapy (TABLE 2). In general, higher levels of soluble factors associated with ongoing immune responses appear to indicate improved prognosis. Increased levels of IL-2 and decreased levels of IL- 6 and TNF in the blood at baseline as well as an increase in IL-4 levels on treatment were all associated with improved response to ICIs in patients with small cell lung cancer ${ }^{129}$. Moreover, a study of patients with NSCLC found that increased serum levels of numerous inflammatory cytokines were associated with improved response to anti-PD1 therapy and overall survival ${ }^{130}$. By contrast, high serum levels of the neutrophil chemokine IL-8 have recently been associated with poor response to ICIs in patients with melanoma, 
Table 2 | Peripheral immune biomarkers in cancer

\begin{tabular}{|c|c|c|c|}
\hline $\begin{array}{l}\text { Peripheral blood } \\
\text { immune feature }\end{array}$ & Prognosis & Tumour type ${ }^{a}$ & Refs \\
\hline $\begin{array}{l}\text { High neutrophil to } \\
\text { lymphocyte ratio }\end{array}$ & Worse response to $\mathrm{ICls}$ & $\begin{array}{l}\text { Melanoma }{ }^{\mathrm{M} / \mathrm{NM}} \text {, } \\
\text { NSCLC, renal cell } \\
\text { carcinoma }^{\mathrm{M}}\end{array}$ & $\begin{array}{l}132,133, \\
136-138\end{array}$ \\
\hline High serum IL-8 & Worse response to $\mathrm{ICls}$ & $\begin{array}{l}\text { Melanoma, NSCLC, } \\
\text { SCLCM/NM }\end{array}$ & 129,131 \\
\hline Low serum LDH & Better response to $\mathrm{ICls}$ & $\begin{array}{l}\text { Melanoma } \\
\text { NSCLC }^{\mathrm{M} / \mathrm{NM}}\end{array}$ & 132,133 \\
\hline $\begin{array}{l}\text { Higher relative eosinophil } \\
\text { count }\end{array}$ & Better response to $\mathrm{ICls}$ & Melanoma $a^{\mathrm{M} / \mathrm{NM}}$ & 132 \\
\hline $\begin{array}{l}\text { Higher relative } \\
\text { lymphocyte count }\end{array}$ & Better response to $\mathrm{ICls}$ & Melanoma ${ }^{\mathrm{M} / \mathrm{NM}}$ & 132 \\
\hline Higher IL-2 at baseline & Better response to $\mathrm{ICls}$ & $\mathrm{SCLC}^{\mathrm{M} / \mathrm{NM}}$ & 129 \\
\hline Lower IL-6 at baseline & Better response to $\mathrm{ICls}$ & $\mathrm{SCLCM/NM}$ & 129 \\
\hline Lower TNF at baseline & Better response to $\mathrm{ICls}$ & $\mathrm{SCLC}^{\mathrm{M} / \mathrm{NM}}$ & 129 \\
\hline Increase IL-4 on treatment & Better response to $\mathrm{ICls}$ & $\mathrm{SCLC}^{\mathrm{M} / \mathrm{NM}}$ & 129 \\
\hline $\begin{array}{l}\text { Higher TCR repertoire } \\
\text { diversity at baseline }\end{array}$ & Better response to $\mathrm{ICls}$ & $\begin{array}{l}\text { Melanoma }{ }^{\mathrm{M}} \text {, classical } \\
\text { Hodgkin lymphoma }\end{array}$ & 115,134 \\
\hline $\begin{array}{l}\text { Fewer M-MDSCs at } \\
\text { baseline }\end{array}$ & $\begin{array}{l}\text { Prolonged overall } \\
\text { survival after ICI } \\
\text { (anti-CTLA4) therapy, } \\
\text { better response to } \\
\text { neoantigen vaccine } \\
\text { immunotherapy }\end{array}$ & $\begin{array}{l}\text { Melanoma }{ }^{\mathrm{M} / \mathrm{NM}} \\
\text { (anti-CTLA4), diffuse } \\
\text { midline glioma } \\
\text { (peptide vaccine + } \\
\text { poly-ICLC) }\end{array}$ & $139-144$ \\
\hline $\begin{array}{l}\text { More CD45RA-FOXP } 3^{\text {hi }} \\
\mathrm{T}_{\text {reg }} \text { cells at baseline }\end{array}$ & Relapse after surgery & Breast cancer & 53 \\
\hline $\begin{array}{l}\text { More naive and effector } \\
\mathrm{T}_{\text {reg }} \text { cells at baseline }\end{array}$ & $\begin{array}{l}\text { Poor response to } \\
\text { chemotherapy } \\
\text { (platinum based with or } \\
\text { without anti-VEGFA) }\end{array}$ & NSCLCM & 145 \\
\hline More $_{\text {reg }}$ cells at baseline & $\begin{array}{l}\text { Improved response to } \\
\text { ICls (anti-CTLA4) }\end{array}$ & Melanoma $^{\mathrm{M}}$ & 140 \\
\hline $\begin{array}{l}\text { More mature natural killer } \\
\text { cells at baseline }\end{array}$ & $\begin{array}{l}\text { Better response to } \mathrm{ICls} \\
\text { (anti-PD1) }\end{array}$ & $\begin{array}{l}\text { Classical Hodgkin } \\
\text { lymphoma }\end{array}$ & 115 \\
\hline $\begin{array}{l}\text { More } \mathrm{CD}^{-} \mathrm{CD}^{-} 8^{+} \mathrm{CD} 4^{+} \\
\text {granzyme } \mathrm{B}^{+} \text {at baseline }\end{array}$ & $\begin{array}{l}\text { Better response to } \mathrm{ICls} \\
\text { (anti-PD1) }\end{array}$ & $\begin{array}{l}\text { Classical Hodgkin } \\
\text { lymphoma }\end{array}$ & 115 \\
\hline $\begin{array}{l}\text { More } \mathrm{CD} 127^{\mathrm{lo}} \mathrm{PD} 1^{\mathrm{lo}} \mathrm{CD} 4^{+} \\
\text {T cells after treatment }\end{array}$ & $\begin{array}{l}\text { Better response to } \\
\text { ICIs (anti-CTLA4 and } \\
\text { GM-CSF) }\end{array}$ & Melanoma $^{\mathrm{M}}$ & 92 \\
\hline $\begin{array}{l}\text { Proliferating and/or clonal } \\
\text { expansion } C D 8^{+} T \text { cells } \\
\text { after treatment }\end{array}$ & $\begin{array}{l}\text { Better response to } \mathrm{ICls} \\
\text { (anti-PD1 or anti-PD1 + } \\
\text { anti-CTLA4) }\end{array}$ & Melanoma $^{\mathrm{M}}$ & $110,146,147$ \\
\hline $\begin{array}{l}\text { More } T_{\text {reg }} \text { cells after } \\
\text { treatment }\end{array}$ & $\begin{array}{l}\text { Better response to } \mathrm{ICls} \\
\text { (anti-PD1) }\end{array}$ & NSCLC & 148,149 \\
\hline $\begin{array}{l}\text { Fewer PMN-MDSCs after } \\
\text { treatment }\end{array}$ & $\begin{array}{l}\text { Better response to } \mathrm{ICls} \\
\text { (anti-PD1) }\end{array}$ & NSCLC & 148,149 \\
\hline \multicolumn{4}{|c|}{$\begin{array}{l}\text { ICI, immune checkpoint inhibitor; M-MDSC, mononuclear myeloid-derived suppressor cell; } \\
\text { NSCLC, non-small-cell lung cancer; PMN-MDSC, polymorphonuclear myeloid-derived } \\
\text { suppressor cell; SCLC, small-cell lung cancer; TCR, T cell receptor; } T_{\text {reg }} \text { cell, regulatory T cell; } \\
\text { VEGFA, vascular endothelial growth factor A. a Superscript }{ }^{M} \text { indicates that this observation } \\
\text { was specifically made in metastatic disease, whereas }{ }^{N M} \text { indicates that the observation was } \\
\text { specifically made in non-metastatic disease. }\end{array}$} \\
\hline
\end{tabular}

NSCLC and small cell lung cancer ${ }^{129,131}$. This observation perhaps reflects the immunosuppressive roles that neutrophils can play in antitumour immune response. In addition, low serum LDH was found to be an indicator of response to ICIs in patients with melanoma ${ }^{132}$ and NSCLC ${ }^{133}$, and the cellular and molecular mechanisms that underlie this association merit further investigation. Beyond secreted factors, studies have also examined whether the repertoire of lymphocyte antigen receptors in circulation provides prognostic information. Baseline diversity of TCR repertoires was also shown to predict responses to anti-PD1 and anti-CTLA4 ICIs in metastatic melanoma and classical Hodgkin lymphoma ${ }^{115,134}$.

Peripheral cellular biomarkers before treatment. Cellular biomarkers from peripheral blood are another promising approach to improve patient stratification. Simple metrics quantified from routine complete blood counts have been shown to associate with patient prognosis in various human malignancies. Of these, the neutrophil to lymphocyte ratio has emerged as a negative prognostic indicator in patients with various individual cancer types as well as in meta analyses ${ }^{19,135}$. Moreover, in patients with melanoma, NSCLC and renal cell carcinoma, response to immunotherapy with ICIs is also associated with the neutrophil to lymphocyte ratio $^{132,133,136-138}$. ICI response in patients with melanoma was also associated with higher relative eosinophil counts and higher relative lymphocyte counts compared with non-responders ${ }^{132}$. Detailed cellular analyses, generally performed by flow cytometry, have also identified specific cell populations in peripheral blood that associate with outcomes. Various studies have identified associations between circulating immunosuppressive cell subsets and response to therapy. For instance, patients with melanoma with lower levels of circulating M-MDSCs at baseline were significantly more likely to achieve prolonged overall survival following antiCTLA4 ICI ${ }^{139-143}$. Similarly, in patients with diffuse midline glioma, lower frequencies of M-MDSCs in peripheral blood predict improved response to neoantigen vaccine immunotherapy ${ }^{144}$. Beyond myeloid suppressive cells, a recent study demonstrated that the baseline abundance of a subset of circulating $\mathrm{T}_{\text {reg }}$ cells defined as CD45RA-FOXP $3^{\text {hi }}$ were predictive of relapse after patients with breast cancer underwent surgery ${ }^{53}$. High levels of circulating naive and effector $\mathrm{T}_{\text {reg }}$ cells in patients with NSCLC were also associated with poor response to chemotherapy ${ }^{145}$. Conversely, in the context of immunotherapy, one study found that higher levels of circulating $\mathrm{T}_{\text {reg }}$ cells predicted improved response to anti-CTLA4 ICI in melanoma ${ }^{140}$. On the other hand, cytotoxic cell subsets in the periphery have been shown to associated with improved response. The abundances of mature NK cells and a subset of cells defined by co-expression of CD68, CD4 and granzyme B were found to associated with response to anti-PD1 therapy in classical Hodgkin lymphoma patients ${ }^{115}$. Therefore, although there remains no systemic immune biomarker that is widely used to guide patient treatment, recent progress in this area has been quite encouraging.

Peripheral cellular biomarkers on treatment. In addition to baseline indicators of patient outcome, various recent reports have emerged indicating that several features of immune cells in peripheral blood of patients with cancer early after immunotherapy are indicative of good outcomes. A pattern has emerged indicating that 
early signs of activated or proliferating lymphocytes are associated with an improved likelihood of response. A study from our group identified circulating CD4 ${ }^{+}$ $\mathrm{T}$ cells with low expression of both CD127 and PD1 associated with response to anti-CTLA4 and GM-CSF in patients with melanoma ${ }^{92}$. In addition, various recent studies have also shown that $\mathrm{CD}^{+} \mathrm{T}$ cell proliferation and expansion in peripheral blood is associated with response to ICIs. In melanoma, the ratio of peripheral $\mathrm{T}$ cell proliferation to tumour burden was shown to be associated with response to anti-PD1 therapy ${ }^{146}$. In this study, the peak of $\mathrm{CD}^{+} \mathrm{T}$ cell proliferation occurred after one or two cycles of therapy ( 3 or 6 weeks), and proliferating cells (identified as $\mathrm{Ki}^{6} 7^{+}$) were enriched for PD1 expression. Building on this finding, several groups recently demonstrated that the expansion of specific $\mathrm{T}$ cell clones in peripheral blood of patients with cancer early after ICI therapy were associated with clinical responses. Clonal expansion of effector memory-like $\mathrm{CD}^{+} \mathrm{T}$ cells in peripheral blood followed by tumour infiltration was associated with response to ICIs in patients with melanoma ${ }^{110,147}$. Moreover, patients across several malignancies with evidence of clonal expansion by gene expression analysis experienced greater progression-free survival when treated with anti-PDL1 therapy ${ }^{109}$. A study of NSCLC has also found that an increase in circulating $\mathrm{T}_{\text {reg }}$ cells after treatment with anti-PD1 leads to a favourable response to treatment, whereas circulating PMN-MDSC frequencies decreased in responders ${ }^{148,149}$. Thus, a series of recent studies have identified on-treatment biomarkers captured in peripheral blood analyses that both support the importance of systemic immune responses in immunotherapy and provide opportunities for improving patient care through immune monitoring.

\section{Conclusion and future perspectives}

The widespread adoption of high-throughput, high-dimensional, single-cell technologies has led to many important discoveries and atlases of diverse tumour immune microenvironments at steady state and with therapy ${ }^{150-155}$. The vast majority of these studies have focused on the tumour itself rather than assessing how the global immune macroenvironment is altered compared with healthy individuals or how the peripheral immune landscape changes in response to therapy. A complete understanding of cancer and the host immune responses across diverse tumour types, patient populations and therapies requires detailed understanding not only of the TME but also of the macroenvironmental alterations in immune organization. Unbiased single-cell technologies measuring the transcriptome, epigenome and proteome as well as multiple modalities simultaneously will play an integral role in the construction of comprehensive organism-scale reference maps of the immune system in cancer and of the impact of various cancer therapies. Establishing distinct types of peripheral immune organization in patients with cancer will aid personalized medicine efforts by informing the context in which therapeutic interventions will be introduced. Such studies in the context of therapy will also inform how the peripheral immune response is regulated and dysregulated during effective or ineffective immune responses. Although many alterations to immune organization have been observed in the periphery of individuals burdened with tumours, the mechanisms driving many of these features remain unknown. Thus, future studies will also need to provide mechanistic insights into how peripheral immune reorganization is driven in order to enable the design of therapeutic strategies that restore a disrupted immune system to a healthy homeostatic immune set point. Our group found that surgical resection or blockade of specific cytokines in multiple tumour models restored many peripheral immune perturbations, suggesting that the tumour immune macroenvironment is remarkably plastic ${ }^{28}$. Pairing single-cell measurements from the tumour and periphery may facilitate the identification of simplified biomarkers that can be easily sampled through blood draws and provide important clinical information to help guide treatment decisions ${ }^{53,115,134,156}$.

Beyond the reorganization of the immune system in cancer, accumulating evidence also indicates that the tumour-burdened immune state does not function in the same way as an unperturbed immune system. The development of de novo antitumour immune responses orchestrated from the periphery are critical for immunotherapeutic efficacy. Therefore, any functional abnormalities within a tumour-burdened immune system may lead to suboptimal immunotherapeutic efficacy. We propose that an important avenue of future research is the identification of emergent functional properties of the tumour-burdened immune state. A growing body of evidence suggests that systemic dendritic cell dysfunction is a cause of blunted $\mathrm{CD}^{+} \mathrm{T}$ cell proliferation and differentiation in the context of cancer. Although dendritic cell-focused treatments such as anti-CD40 agonist immunotherapy ${ }^{28,39,157}$, poly-ICLC ${ }^{158}$ and FLT3L $\mathrm{L}^{39,159}$ can overcome impaired dendritic cell function and paucity, the precise mechanisms underlying the dendritic cell dysfunction remain incompletely understood. As dendritic cells are the most important cell type for initiating $\mathrm{T}$ cell responses in cancer, deciphering why dendritic cells are functionally impaired in the periphery of individuals burdened with tumours is imperative. To date, studies have evaluated the capacity of tumour-bearing mice to mount type 1 immune responses. As the immune system can be engaged in substantially different ways based on the context of the challenge, an intriguing next step is to drive functionally distinct immune responses in tumour-burdened mice such as parasite and allergen challenges. Diverse functional challenges will elucidate emergent functional immunological alterations that are undetectable by simply examining cell population frequencies and phenotypes. Importantly, diverse functional challenges may also reveal aspects of immunity that are not perturbed by the tumour burden and, thus, inform therapeutic interventions that utilize unperturbed aspects of the immune system. Another important strategy is to design studies to thoroughly evaluate human immune responses to new challenges in patients with cancer who are treatment naive. Detailed single-cell analysis 
of vaccine responses in patients with cancer as well as longitudinal monitoring of patients with high-risk mutations or organoid systems could be utilized to define the functionality of the tumour-burdened immune state in humans. These types of studies are an important step towards identifying weaknesses, or perhaps new strengths, in immune function that can rationally inform the design and implementation of new cancer immunotherapies. Additionally, as patients with cancer represent a susceptible population for infection, these studies can inform vaccination formulations and therapeutic interventions to protect this vulnerable patient population from secondary infections. Altogether, an improved understanding of how the peripheral immune landscape is perturbed and contributes to tumour control will provide essential next steps for the field.

Published online 9 April 2021
1. Coussens, L. M. \& Werb, Z. Inflammation and cancer. Nature 420, 860-867 (2002).

2. Haslam, A. \& Prasad, V. Estimation of the percentage of US patients with cancer who are eligible for and respond to checkpoint inhibitor immunotherapy drugs. JAMA Netw. Open 2, e192535 (2019).

3. Hegde, P. S. $\&$ Chen, D. S. Top 10 challenges in cancer immunotherapy. Immunity 52, 17-35 (2020).

4. Schultze, J. L., Mass, E. \& Schlitzer, A. Emerging principles in myelopoiesis at homeostasis and during infection and inflammation. Immunity 50, 288-301 (2019).

5. Masopust, D. \& Schenkel, J. M. The integration of $\mathrm{T}$ cell migration, differentiation and function. Nat. Rev. Immunol. 13, 309-320 (2013).

6. Hanahan, D. \& Coussens, L. M. Accessories to the crime: functions of cells recruited to the tumor microenvironment. Cancer Cell 21, 309-322 (2012).

7. Gonzalez, H., Hagerling, C. \& Werb, Z. Roles of the immune system in cancer: from tumor initiation to metastatic progression. Genes Dev. 32, 1267-1284 (2018).

8. Gabrilovich, D. I., Ostrand-Rosenberg, S. \& Bronte, V. Coordinated regulation of myeloid cells by tumours Nat. Rev. Immunol. 12, 253-268 (2012).

9. Jaillon, S. et al. Neutrophil diversity and plasticity in tumour progression and therapy. Nat. Rev. Cancer 20 485-503 (2020).

10. Canè, S. et al. The endless saga of monocyte diversity. Front. Immunol. 10, 1786 (2019).

11. Almand, B. et al. Increased production of immature myeloid cells in cancer patients: a mechanism of immunosuppression in cancer. J. Immunol. 166 678-689 (2001)

12. Casbon, A. J. et al. Invasive breast cancer reprograms early myeloid differentiation in the bone marrow to generate immunosuppressive neutrophils. Proc. Natl Acad. Sci. USA 112, E566-E575 (2015).

13. Wu, W. C. et al. Circulating hematopoietic stem and progenitor cells are myeloid-biased in cancer patients. Proc. Natl Acad. Sci. USA 111, 4221-4226 (2014). This paper demonstrates that haematopoietic stem and progenitor cell populations are mobilized into the blood and biased towards myeloid differentiation in multiple diverse human tumour types.

14. Kersten, K. et al. Mammary tumor-derived CCL2 enhances pro-metastatic systemic inflammation through upregulation of IL $1 \beta$ in tumor-associated macrophages. Oncoimmunology 6, e 1334744 (2017).

15. Coffelt, S. B. et al. IL-17-producing $\gamma \delta$ T cells and neutrophils conspire to promote breast cancer metastasis. Nature 522, 345-348 (2015).

16. Giles, A. J. et al. Activation of hematopoietic stem/ progenitor cells promotes immunosuppression within the pre-metastatic niche. Cancer Res. 76, 1335-1347 (2016).

17. Sio, A. et al. Dysregulated hematopoiesis caused by mammary cancer is associated with epigenetic changes and Hox gene expression in hematopoietic cells. Cancer Res. 73, 5892-5904 (2013).

18. Meyer, M. A. et al. Breast and pancreatic cancer interrupt IRF8-dependent dendritic cell development to overcome immune surveillance. Nat. Commun. $\mathbf{9}$, 1250 (2018)

This paper demonstrates that disruption of haematopoiesis in human and mouse breast and pancreatic cancer decreases bone marrow production of dendritic cells in the periphery. This deficit then results in impaired response to a secondary peripheral challenge of a Matrigel plug containing OVA.

19. Templeton, A. J. et al. Prognostic role of neutrophilto-lymphocyte ratio in solid tumors: a systematic review and meta-analysis. J. Natl Cancer Inst. 106, dju124 (2014).
20. Shojaei, F. et al. G-CSF-initiated myeloid cell mobilization and angiogenesis mediate tumor refractoriness to anti-VEGF therapy in mouse models. Proc. Natl Acad. Sci. USA 106, 6742-6747 (2009).

21. Morales, J. K., Kmieciak, M., Knutson, K. L., Bear, H. D. \& Manjili, M. H. GM-CSF is one of the main breast tumor-derived soluble factors involved in the differentiation of $\mathrm{CD} 11 \mathrm{~b}^{-} \mathrm{Gr} 1^{-}$bone marrow progenitor cells into myeloid-derived suppressor cells. Breast Cancer Res. Treat. 123, 39-49 (2010).

22. Bayne, L. J. et al. Tumor-derived granulocytemacrophage colony-stimulating factor regulates myeloid inflammation and $\mathrm{T}$ cell immunity in pancreatic cancer. Cancer Cell 21, 822-835 (2012).

23. Raccosta, L. et al. The oxysterol-CXCR2 axis plays a key role in the recruitment of tumor-promoting neutrophils. J. Exp. Med. 210, 1711-1728 (2013).

24. Dominguez, C., McCampbell, K. K., David, J. M $\&$ Palena, C. Neutralization of IL-8 decreases tumor PMN-MDSCs and reduces mesenchymalization of claudin-low triple-negative breast cancer. JCl Insight 2 e94296 (2017).

25. Al Sayed, M. F. et al. T-cell-secreted TNFa induces emergency myelopoiesis and myeloid-derived suppressor cell differentiation in cancer. Cancer Res. 79, 346-359 (2019)

26. Peinado, $\mathrm{H}$. et al. Melanoma exosomes educate bone marrow progenitor cells toward a pro-metastatic phenotype through MET. Nat. Med. 18, 883-891 (2012).

27. Wellenstein, M. D. et al. Loss of p53 triggers WNTdependent systemic inflammation to drive breast cancer metastasis. Nature 572, 538-542 (2019)

28. Allen, B. M. et al. Systemic dysfunction and plasticity of the immune macroenvironment in cancer models. Nat. Med. 26, 1125-1134 (2020).

This paper demonstrates that the systemic immune landscape in many mouse tumour models is substantially perturbed yet can be restored by tumour resection or cytokine treatment. Furthermore, new immune responses in the periphery are significantly blunted but can be rescued by agonist anti-CD40 treatment or surgical resection

29. Hildner, K. et al. Batf3 deficiency reveals a critical role for $\mathrm{CD} 8 \mathrm{a}^{+}$dendritic cells in cytotoxic T cell immunity. Science 322, 1097-1100 (2008)

30. Binnewies, M. et al. Unleashing type- 2 dendritic cells to drive protective antitumor $\mathrm{CD} 4^{+} \mathrm{T}$ cell immunity. Cell 177, 556-571.e16 (2019).

31. Mastelic-Gavillet, B. et al. Quantitative and qualitative impairments in dendritic cell subsets of patients with ovarian or prostate cancer. Eur. J. Cancer 135 173-182 (2020)

32. Della Bella, S. et al. Altered maturation of peripheral blood dendritic cells in patients with breast cancer. Br. J. Cancer 89, 1463-1723 (2003).

33. Tabarkiewicz, J., Rybojad, P., Jablonka, A. \& Rolinski, J. $\mathrm{CD} 1 \mathrm{C}^{+}$and $\mathrm{CD} 303^{+}$dendritic cells in peripheral blood, lymph nodes and tumor tissue of patients with non-small cell lung cancer. Oncol. Rep. 19, 237-243 (2008).

34. Van Cruijsen, $\mathrm{H}$. et al. Sunitinib-induced myeloid lineage redistribution in renal cell cancer patients: $C D 1 \mathrm{c}^{+}$ dendritic cell frequency predicts progression-free survival. Clin. Cancer Res. 14, 5884-5892 (2008).

35. Almand, B. et al. Clinical significance of defective dendritic cell differentiation in cancer. Clin. Cancer Res. 6, 1755-1766 (2000).

36. Failli, A., Legitimo, A., Orsini, G., Romanini, A. $\&$ Consolini, R. Numerical defect of circulating dendritic cell subsets and defective dendritic cell generation from monocytes of patients with advanced melanoma. Cancer Lett. 337, 184-192 (2013).

37. Gabrilovich, D. et al. Vascular endothelial growth factor inhibits the development of dendritic cells and dramatically affects the differentiation of multiple hematopoietic lineages in vivo. Blood 92, 4150-4166 (1998).

38. Gabrilovich, D. I. et al. Production of vascular endothelial growth factor by human tumors inhibits the functional maturation of dendritic cells. Nat. Med. 2, 1096-1103 (1996).

39. Lin, J. H. et al. Type 1 conventional dendritic cells are systemically dysregulated early in pancreatic carcinogenesis. J. Exp. Med. 217, e201906733 (2020).

This paper demonstrates that peripheral dendritic cells are decreased via tumour-secreted IL-6 inducing apoptosis. This deficit then leads to an impaired peripheral response to vaccination that can be rescued by combination agonist anti-CD40 and FLT3L treatment.

40. Tjomsland, V. et al. Semi mature blood dendritic cells exist in patients with ductal pancreatic adenocarcinoma owing to inflammatory factors released from the tumor. PLOS ONE 5, e13441 (2010).

41. Dudek, A. M., Martin, S., Garg, A. D. \& Agostinis, P. Immature, semi-mature, and fully mature dendritic cells: toward a DC-cancer cells interface that augments anticancer immunity. Front. Immunol. 4, 438 (2013).

42. Ray-Coquard, I. et al. Lymphopenia as a prognostic factor for overall survival in advanced carcinomas, sarcomas, and lymphomas. Cancer Res. 69 , 5383-5391 (2009).

43. Manuel, M. et al. Lymphopenia combined with low TCR diversity (divpenia) predicts poor overall survival in metastatic breast cancer patients. Oncoimmunology 1, 432-440 (2012).

44. Liu, Y. Y. et al. Characteristics and prognostic significance of profiling the peripheral blood T-cell receptor repertoire in patients with advanced lung cancer. Int. J. Cancer 145, 1423-1431 (2019).

45. Cui, J. H. et al. TCR repertoire as a novel indicator for immune monitoring and prognosis assessment of patients with cervical cancer. Front. Immunol. 9, 2729 (2018).

46. Tumeh, P. C. et al. PD-1 blockade induces responses by inhibiting adaptive immune resistance. Nature $\mathbf{5 1 5}$, 568-571 (2014)

47. Britanova, O. V. et al. Age-related decrease in TCR repertoire diversity measured with deep and normalized sequence profiling. J. Immunol. 192, 2689-2698 (2014).

48. Baum, P. D. et al. Blood T-cell receptor diversity decreases during the course of HIV infection, but the potential for a diverse repertoire persists. Blood 119 3469-3477 (2012).

49. Verronèse, E. et al. Immune cell dysfunctions in breast cancer patients detected through whole blood multiparametric flow cytometry assay. Oncoimmunology 5 e1100791 (2015).

50. Wang, L. et al. IL6 signaling in peripheral blood T cells predicts clinical outcome in breast cancer. Cancer Res. 77, 1119-1126 (2017)

51. Wolf, A. M. et al. Increase of regulatory T cells in the peripheral blood of cancer patients. Clin. Cancer Res. 9, 606-612 (2003).

52. Ahmadzadeh, M. et al. Tumor-infiltrating human CD4 ${ }^{+}$ regulatory T cells display a distinct TCR repertoire and exhibit tumor and neoantigen reactivity. Sci. Immunol. 4, eaao4310 (2019).

53. Wang, L. et al. Connecting blood and intratumoral $\mathrm{T}_{\text {reg }}$ cell activity in predicting future relapse in breast cancer. Nat. Immunol. 20, 1220-1230 (2019).

54. Yuen, G. J., Demissie, E. \& Pillai, S. B lymphocytes and cancer: a love-hate relationship. Trends Cancer $\mathbf{2}$. 747-757 (2016).

55. Wang, W. et al. CD19+CD24 ${ }^{\text {hi }} C D 38^{\text {hi }} B_{\text {regs }}$ involved in downregulate helper $T$ cells and upregulate regulatory $\mathrm{T}$ cells in gastric cancer. Oncotarget 6, 33486-33499 (2015). 
56. Murakami, Y. et al. Increased regulatory B cells are involved in immune evasion in patients with gastric cancer. Sci. Rep. 9, 13083 (2019).

57. Zhou, J. et al. Enhanced frequency and potentia mechanism of B regulatory cells in patients with lung cancer. J. Transl Med. 12, 304 (2014).

58. Olkhanud, P. B. et al. Tumor-evoked regulatory B cells promote breast cancer metastasis by converting resting $\mathrm{CD}^{+} \mathrm{T}$ cells to T-regulatory cells. Cancer Res. 71, 3505-3515 (2011)

59. Shimasaki, N., Jain, A. \& Campana, D. NK cells for cancer immunotherapy. Nat. Rev. Drug Discov. 19 200-218 (2020).

60. Mamessier, E. et al. Human breast cancer cells enhance self tolerance by promoting evasion from NK cell antitumor immunity. J. Clin. Invest. 121 , 3609-3622 (2011)

61. Ménard, C. et al. Natural killer cell IFN- $\gamma$ levels predict long-term survival with imatinib mesylate therapy in gastrointestinal stromal tumor-bearing patients. Cancer Res. 69, 3563-3569 (2009).

62. Charrier, M. et al. Circulating innate immune markers and outcomes in treatment-naïve advanced non-small cell lung cancer patients. Eur. J. Cancer 108, 88-96 (2019).

63. Semeraro, M. et al. Clinical impact of the NKp30/ B7-H6 axis in high-risk neuroblastoma patients. Sci. Transl Med. 7, 283 ra55 (2015).

64. Platonova, S. et al. Profound coordinated alterations of intratumoral NK cell phenotype and function in lung carcinoma. Cancer Res. 71, 5412-5422 (2011).

65. Shaked, $Y$. The pro-tumorigenic host response to cancer therapies. Nat. Rev. Cancer 19, 667-685 (2019).

66. Gustafson, C. E. et al. Immune cell repertoires in breast cancer patients after adjuvant chemotherapy 5, e 134569 (2020)

67. Talebian Yazdi, M. et al. Standard radiotherapy but not chemotherapy impairs systemic immunity in nonsmall cell lung cancer. Oncoimmunology 5, e 1255393 (2016).

68. van Meir, H. et al. Impact of (chemo)radiotherapy on immune cell composition and function in cervical cancer patients. Oncoimmunology 6, e 1267095 (2017).

69. Wesolowski, R. et al. Circulating myeloid-derived suppressor cells increase in patients undergoing neo-adjuvant chemotherapy for breast cancer. Cancer Immunol. Immunother. 66, 1437-1447 (2017).

70. Larsson, A. M., Roxå, A., Leandersson, K \& Bergenfelz, C. Impact of systemic therapy on circulating leukocyte populations in patients with metastatic breast cancer. Sci. Rep. 9, 13451 (2019)

71. Valdés-Ferrada, J. et al. Peripheral blood classical monocytes and plasma interleukin 10 are associated to neoadjuvant chemotherapy response in breast cancer patients. Front. Immunol. 11, 1413 (2020).

72. Axelrod, M. L. et al. Changes in peripheral and local tumor immunity after neoadjuvant chemotherapy reshape clinical outcomes in patients with breast cancer. Clin. Cancer Res. 26, 5668-5681 (2020).

73. Yu, W. D., Sun, G., Li, J., Xu, J. \& Wang, X Mechanisms and therapeutic potentials of cancer immunotherapy in combination with radiotherapy and/or chemotherapy. Cancer Lett. 452, 66-70 (2019).

74. Luo, Q., Zhang, L., Luo, C. \& Jiang, M. Emerging strategies in cancer therapy combining chemotherapy with immunotherapy. Cancer Lett. 454, 191-203 (2019).

75. Bailly, C., Thuru, X. \& Quesnel, B. Combined cytotoxic chemotherapy and immunotherapy of cancer: modern times. NAR Cancer 2, zcaa002 (2020).

76. Tohme, S., Simmons, R. L. \& Tsung, A. Surgery for cancer: a trigger for metastases. Cancer Res. 77, 1548-1552 (2017)

77. Tohme, S. et al. Neutrophil extracellular traps promote the development and progression of liver metastases after surgical stress. Cancer Res. 76, 1367-1380 (2016)

78. Krall, J. A. et al. The systemic response to surgery triggers the outgrowth of distant immune-controlled tumors in mouse models of dormancy. Sci. Transl Med. 10, eaan3464 (2018)

79. Bosiljcic, M. et al. Targeting myeloid-derived suppressor cells in combination with primary mammary tumo resection reduces metastatic growth in the lungs. Breast Cancer Res. 21, 103 (2019).

80. Kallis, M. P. et al. Pharmacological prevention of surgery-accelerated metastasis in an animal model of osteosarcoma. J. Transl. Med. 18, 183 (2020).

81. Ananth, A. A. et al. Surgical stress abrogates pre-existing protective $\mathrm{T}$ cell mediated anti-tumor immunity leading to postoperative cancer recurrence. PLOS ONE 11, e0155947 (2016).

82. Tai, L. H. et al. Preventing postoperative metastatic disease by inhibiting surgery-induced dysfunction in natural killer cells. Cancer Res. 73, 97-107 (2013)

83. Angka, L. et al. Natural killer cell IFN $\gamma$ secretion is profoundly suppressed following colorectal cancer surgery. Ann. Surg. Oncol. 25, 3747-3754 (2018).

84. Danna, E. A. et al. Surgical removal of primary tumor reverses tumor-induced immunosuppression despite the presence of metastatic disease. Cancer Res. 64, 2205-2211 (2004)

85. Mathios, D. et al. Anti-PD-1 antitumor immunity is enhanced by local and abrogated by systemic chemotherapy in GBM. Sci. Transl Med. 8, 370ra180 (2016).

This paper shows that systemic chemotherapy that disrupts systemic immune cell populations abrogates response to checkpoint blockade in glioblastoma. Conversely, local chemotherapy that maintains peripheral immune integrity synergizes with checkpoint blockade.

86. Broz, M. L. et al. Dissecting the tumor myeloid compartment reveals rare activating antigenpresenting cells critical for T cell immunity. Cancer Cell 26. 638-652 (2014).

This paper shows that dendritic cells acquire tumour antigen within the TME, traffic to the tumour dLN and then prime antigen-specific $T$ cells.

87. Roberts, E. W. et al. Critical role for CD $103^{+/ C D} 141$ dendritic cells bearing CCR7 for tumor antigen trafficking and priming of T cell immunity in melanoma. Cancer Cell 30, 324-336 (2016)

88. Salmon, H. et al. Expansion and activation of CD103 dendritic cell progenitors at the tumor site enhances tumor responses to therapeutic PD-L1 and BRAF inhibition. Immunity 44, 924-938 (2016)

89. Spranger, S., Dai, D., Horton, B. \& Gajewski, T. F. Tumor-residing Batf3 dendritic cells are required for effector T cell trafficking and adoptive T cell therapy. Cancer Cell 31, 711-723.e4 (2017).

90. Ruhland, M. K. et al. Visualizing synaptic transfer of tumor antigens among dendritic cells. Cancer Cell 37 786-799.e5 (2020).

91. Chen, D. S. \& Mellman, I. Oncology meets immunology: the cancer-immunity cycle. Immunity 39, 1-10 (2013).

92. Spitzer, M. H. et al. Systemic immunity is required for effective cancer immunotherapy. Cell 168, 487-502 (2017).

This paper demonstrates that trafficking of immun cells is required for effective immunotherapy. Furthermore, a peripheral signature of $\mathrm{CD}^{+} \mathrm{T}$ cells expressing low levels of PD1 and CD127 marked patients who responded to immunotherapy.

93. Fransen, M. F. \& Van Hall, T. Tumor-draining lymph nodes are pivotal in PD-1/PD-L1 checkpoint therapy. JCl Insight 3, e124507 (2018).

94. Lau, J. et al. Tumour and host cell PD-L1 is required to mediate suppression of anti-tumour immunity in mice. Nat. Commun. 8, 14572 (2017).

95. Lin, H. et al. Host expression of PD-L1 determines efficacy of PD-L1 pathway blockade-mediated tumo regression. J. Clin. Invest. 128, 805-815 (2018).

96. Strauss, L. et al. Targeted deletion of PD-1 in myeloid cells induces antitumor immunity. Sci. Immunol. 5, eaay 1863 (2020)

97. Oh, S. A. et al. PD-L1 expression by dendritic cells is a key regulator of T-cell immunity in cancer. Nat. Cancer 1, 681-691 (2020)

This paper shows that deletion of PDL1 specifically in dendritic cells, but not macrophages, greatly restricts tumour growth and amplifies antitumour $\mathrm{CDB}^{+} \mathrm{T}$ cell responses.

98. Dammeijer, F. et al. The PD-1/PD-L1-checkpoint restrains $\mathrm{T}$ cell immunity in tumor-draining lymph nodes. Cancer Cell 38, 1-16 (2020).

99. Peng, Q. et al. PD-L1 on dendritic cells attenuates $T$ cell activation and regulates response to immune checkpoint blockade. Nat. Commun. 11, 4835 (2020)

100. Mayoux, M. et al. Dendritic cells dictate responses to PD-L1 blockade cancer immunotherapy. Sci. Trans/ Med. 12, eaav7431 (2020).

101. Chamoto, K. et al. Mitochondrial activation chemicals synergize with surface receptor PD-1 blockade for T cell-dependent antitumor activity. Proc. Natl Acad. Sci. USA 114, E761-E770 (2017).

102. Philip, M. et al. Chromatin states define tumourspecific T cell dysfunction and reprogramming. Nature 545, 452-456 (2017). This paper shows that intratumoural $\mathrm{T}$ cells acquire a terminal dysfunctional state that can no longer participate in tumour clearance.
103. Scott, A. C. et al. TOX is a critical regulator of tumourspecific T cell differentiation. Nature 571, 270-274 (2019).

104. Khan, O. et al. TOX transcriptionally and epigenetically programs $\mathrm{CD}^{+} \mathrm{T}$ cell exhaustion. Nature 571, 211-218 (2019).

105. Yu, Y.-R. et al. Disturbed mitochondrial dynamics in CD8 ${ }^{+}$TILs reinforce T cell exhaustion. Nat. Immunol. 21, 1540-1551 (2020)

106. Fourcade, J. et al. Upregulation of Tim-3 and PD-1 expression is associated with tumor antigen-specific $\mathrm{CD}^{+} \mathrm{T}$ cell dysfunction in melanoma patients. J. Exp. Med. 207, 2175-2186 (2010)

107. Sade-Feldman, M. et al. Defining T cell states associated with response to checkpoint immunotherapy in melanoma. Cell 175, 998-1013.e20 (2018).

108. Yost, K. E. et al. Clonal replacement of tumor-specific T cells following PD-1 blockade. Nat. Med. 25 , 1251-1259 (2019).

This paper demonstrates that checkpoint blockade immunotherapy drives the expansion of novel $T$ cell clones within the tumour rather than the reinvigoration of existing $\mathrm{T}$ cell clonotypes.

109. Wu, T. D. et al. Peripheral T cell expansion predicts tumour infiltration and clinical response. Nature $\mathbf{5 7 9}$, 274-278 (2020)

This paper shows that expanded T cell clonotypes after immunotherapy can be found in peripheral blood including new $\mathrm{T}$ cell clones that infiltrate the tumour after treatment.

110. Valpione, S. et al. Immune awakening revealed by peripheral $\mathrm{T}$ cell dynamics after one cycle of immunotherapy. Nat. Cancer 1, 210-221 (2020).

111. Kvistborg, P. et al. Anti-CTLA-4 therapy broadens the melanoma-reactive $\mathrm{CD}^{+} \mathrm{T}$ cell response. Sci. Transl Med. 6, 254ra128 (2014).

112. Kamphorst, A. O. et al. Rescue of exhausted CD8 T cells by PD-1-targeted therapies is CD28-dependent. Science 355, 1423-1427 (2017).

113. Hui, E. et al. T cell costimulatory receptor CD28 is a primary target for PD-1-mediated inhibition. Science 355, 1428-1433 (2017)

114. Ferrara, R. et al. Circulating T-cell immunosenescence in patients with advanced non-small cell lung cancer treated with single-agent PD-1/PD-L1 inhibitors or platinum-based chemotherapy. Clin. Cancer Res. 27. 492-503 (2021)

115. Cader, F. Z. et al. A peripheral immune signature of responsiveness to PD-1 blockade in patients with classical Hodgkin lymphoma. Nat. Med. 26 1468-1479 (2020).

116. Vonderheide, R. H. CD40 agonist antibodies in cancer immunotherapy. Annu. Rev. Med. 71, 47-58 (2020).

117. Li, D.-K. \& Wang, W. Characteristics and clinical trial results of agonistic anti-CD40 antibodies in the treatment of malignancies (Review). Oncol. Lett. 20 1-1 (2020).

118. Morrison, A. H. Diamond, M. S. Hay, C. A. Byrne, K. T. \& Vonderheide, R. H. Sufficiency of CD40 activation and immune checkpoint blockade for $\mathrm{T}$ cell priming and tumor immunity. Proc. Natl Acad. Sci. USA 117, 8022-8031 (2020).

119. O'Hara, M. H. et al. CD40 agonistic monoclonal antibody APX005M (sotigalimab) and chemotherapy, with or without nivolumab, for the treatment of metastatic pancreatic adenocarcinoma: an open-label, multicentre, phase $1 \mathrm{~b}$ study. Lancet Oncol. 22, 118-131 (2021)

120. Osborne, L. C. et al. Virus-helminth coinfection reveals a microbiota-independent mechanism of immunomodulation. Science 345, 578-582 (2014).

121. Barnstorf, I. et al. Chronic virus infection compromises memory bystander T cell function in an IL-6/STAT 1 dependent manner. J. Exp. Med. 216, 571-586 (2019).

122. Snell, L. M. et al. CD8 ${ }^{+} \mathrm{T}$ cell priming in established chronic viral infection preferentially directs differentiation of memory-like cells for sustained immunity. Immunity 49, 678-694.e5 (2018).

123. Pollyea, D. A., Brown, J. M. Y. \& Horning, S. J. Utility of influenza vaccination for oncology patients. J. Clin. Oncol. 28, 2481-2490 (2010).

124. Liang, W. et al. Cancer patients in SARS-CoV-2 infection: a nationwide analysis in China. Lancet Oncol. 21, 335-337 (2020)

125. Kuderer, N. M. et al. Clinical impact of COVID-19 on patients with cancer (CCC19): a cohort study. Lancet 395, 1907-1918 (2020).

126. Mittal, R. et al. Phenotypic T cell exhaustion in a murine model of bacterial infection in the setting of pre-existing malignancy. PLOS ONE 9, e93523 (2014). 
127. Russ, A. J. et al. Melanoma-induced suppression of tumor antigen-specific T cell expansion is comparable to suppression of global T cell expansion. Cell. Immunol. 271, 104-109 (2011)

128. Adashek, J., Goloubev, A., Kato, S. \& Kurzrock, R. Immunotherapy trials lack a biomarker for inclusion implications for drug development. J. Immunother. Cancer 8, A192 (2020).

129. Hardy-Werbin, M. et al. Serum cytokine levels as predictive biomarkers of benefit from ipilimumab in small cell lung cancer. Oncoimmunology 8, 1593810 (2019).

130. Boutsikou, E. et al. Tumour necrosis factor interferon- $\gamma$ and interleukins as predictive markers of antiprogrammed cell-death protein-1 treatment in advanced non-small cell lung cancer: a pragmatic approach in clinical practice. Ther. Adv. Med. Oncol. 10,1758835918768238 (2018)

131. Sanmamed, M. F. et al. Changes in serum interleukin-8 (IL-8) levels reflect and predict response to anti-PD-1 treatment in melanoma and non-smallcell lung cancer patients. Ann. Oncol. 28, 1988-1995 (2017).

132. Weide, B. et al. Baseline biomarkers for outcome of melanoma patients treated with pembrolizumab. Clin. Cancer Res. 22, 5487-54967 (2016).

133. Mezquita, L. et al. Association of the lung immune prognostic index with immune checkpoint inhibitor outcomes in patients with advanced non-small cell lung cancer. JAMA Oncol. 4, 351-357 (2018).

134. Hogan, S. A. et al. Peripheral blood TCR repertoire profiling may facilitate patient stratification for immunotherapy against melanoma. Cancer Immunol. Res. 7, 77-85 (2019).

135. Howard, R., Kanetsky, P. A. \& Egan, K. M. Exploring the prognostic value of the neutrophil-to-lymphocyte ratio in cancer. Sci. Rep. 9, 1-10 (2019).

136. Capone, M. et al. Baseline neutrophil-to-lymphocyte ratio (NLR) and derived NLR could predict overall survival in patients with advanced melanoma treated with nivolumab. J. Immunother. Cancer 6, 74 (2018).

137. Lalani, A.-K. A et al. Change in neutrophilto-lymphocyte ratio (NLR) in response to immune checkpoint blockade for metastatic renal cell carcinoma. J. Immunother. Cancer 6, 7 (2018).

138. Ferrucci, P. F. et al. Baseline neutrophils and derived neutrophilto-lymphocyte ratio: prognostic relevance in metastatic melanoma patients receiving ipilimumab. Ann. Oncol. 27, 732-738 (2016)

139. Kitano, S. et al. Computational algorithm-driven evaluation of monocytic myeloid-derived suppressor cell frequency for prediction of clinical outcomes. Cancer Immunol. Res. 2, 812-821 (2014).

140. Martens, A. et al. Baseline peripheral blood biomarkers associated with clinical outcome of advanced melanoma patients treated with ipilimumab. Clin. Cancer Res. 22, 2908-2918 (2016)

141. Gebhardt, C. et al. Myeloid cells and related chronic inflammatory factors as novel predictive markers in melanoma treatment with ipilimumab. Clin. Cancer Res. 21, 5453-5459 (2015)

142. Meyer, C. et al. Frequencies of circulating MDSC correlate with clinical outcome of melanoma patients treated with ipilimumab. Cancer Immunol. Immunother 63, 247-257 (2014).

143. Retseck, J. et al. Long term impact of CTLA4 blockade immunotherapy on regulatory and effector immune responses in patients with melanoma. J. Trans/ Med. 16, 184 (2018)

144. Mueller, S. et al. Mass cytometry detects $\mathrm{H} 3.3 \mathrm{~K} 27 \mathrm{M}$-specific vaccine responses in diffuse midline glioma. J. Clin. Invest. 130, 6325-6337 (2020).

145. Kotsakis, A. et al. Prognostic value of circulating regulatory T cell subsets in untreated non-small cel lung cancer patients. Sci. Rep, 6, 39247 (2016).

146. Huang, A. C. et al. T-cell invigoration to tumour burden ratio associated with anti-PD-1 response. Nature 545 60-65 (2017)

147. Fairfax, B. P. et al. Peripheral CD8 ${ }^{+} T$ cell characteristics associated with durable responses to immune checkpoint blockade in patients with metastatic melanoma. Nat. Med. 26, 193-199 (2020). This paper finds that patients with metastatic melanoma responding to checkpoint blockade show clonal expansion of $\mathrm{CDB}^{+} \mathrm{T}$ cells with a cytotoxic phenotype in peripheral blood.

148. Koh, J. et al. Regulatory (FoxP3+) T cells and TGF- $\beta$ predict the response to anti-PD-1 immunotherapy in patients with non-small cell lung cancer. Sci. Rep. 10, 18994 (2020).

149. Kim, H. R. et al. The ratio of peripheral regulatory T cells to Lox-1 1 polymorphonuclear myeloid-derived suppressor cells predicts the early response to antiPD-1 therapy in patients with non-small cell lung cancer. Am. J. Respir Crit. Care Med. 199, 243-246 (2019).

150. Tirosh, I. et al. Dissecting the multicellular ecosystem of metastatic melanoma by single-cell RNA-seq. Science 352, 189-196 (2016)

151. Gubin, M. M. et al. High-dimensional analysis delineates myeloid and lymphoid compartment remodeling during successful immune-checkpoint cancer therapy. Cell 175, 1014-1030.e19 (2018).

152. Azizi, E. et al. Single-cell map of diverse immune phenotypes in the breast tumor microenvironment. Cell 174, 1293-1308 (2018)

153. Zilionis, R. et al. Single-cell transcriptomics of human and mouse lung cancers reveals conserved myeloid populations across individuals and species. Immunity 50, 1317-1334.e10 (2019)

154. Wagner, J. et al. A single-cell atlas of the tumor and immune ecosystem of human breast cancer. Cell 177 1-16 (2019).

155. Steele, N. G. et al. Multimodal mapping of the tumor and peripheral blood immune landscape in human pancreatic cancer. Nat. Cancer 1, 1097-1112 (2020)

156. Nabet, B. Y. et al. Noninvasive early identification of therapeutic benefit from immune checkpoint inhibition. Cell 183, 363-376.e13 (2020)

157. O'Hara, M. H. et al. A phase lb study of CD40 agonistic monoclonal antibody APX005M together with gemcitabine (Gem) and nab-paclitaxel (NP) with or without nivolumab (Nivo) in untreated metastatic ductal pancreatic adenocarcinoma (PDAC) patients. Cancer Res. 79, CT004 (2019)

158. Kyi, C. et al. Therapeutic immune modulation against solid cancers with intratumoral poly-ICLC: a pilot trial. Clin. Cancer Res. 24, 4937-4948 (2018)

159. Bhardwaj, N. et al. Flt3 ligand augments immune responses to anti-DEC-205-NY-ESO-1 vaccine through expansion of dendritic cell subsets. Nat. Cancer 1 , 1204-1217 (2020).

160. Brandau, S. et al. Myeloid-derived suppressor cells in the peripheral blood of cancer patients contain a subset of immature neutrophils with impaired migratory properties. J. Leukoc. Biol. 89, 311-317 (2011).

161. Raychaudhuri, B. et al. Myeloid-derived suppressor cell accumulation and function in patients with newly diagnosed glioblastoma. Neuro. Oncol. 13, 591-599 (2011).

162. Zhu, Y. P. et al. Identification of an early unipotent neutrophil progenitor with pro-tumoral activity in mouse and human bone marrow. Cell Rep. 24, 2329-2341.e8 (2018)

163. Sagiv, J. Y. et al. Phenotypic diversity and plasticity in circulating neutrophil subpopulations in cancer. Cell Rep. 10, 562-573 (2015)

164. Chittezhath, M. et al. Molecular profiling reveals tumor-promoting phenotype of monocytes and macrophages in human cancer progression. Immunity 41, 815-294 (2014)

165. Filipazzi, P et al. Identification of a new subset of myeloid suppressor cells in peripheral blood of melanoma patients with modulation by a granulocytemacrophage colony-stimulation factor-based antitumo vaccine. J. Clin. Oncol. 25, 2546-2553 (2007).

166. Hoechst, B. et al. A new population of myeloid-derived suppressor cells in hepatocellular carcinoma patients induces $\mathrm{CD} 4{ }^{+} \mathrm{CD} 25+$ Foxp3 $+\mathrm{T}$ cells. Gastroenterology 135, 234-243 (2008).

167. Poschke, I., Mougiakakos, D., Hansson, J., Masucci, G. V. \& Kiessling, R. Immature immunosuppressive $\mathrm{CD}_{14} 4^{+} \mathrm{HLA}^{-} \mathrm{DR}^{-} /$low cells in melanoma patients are Stat3hi and overexpress CD80, CD83, and DC-sign. Cancer Res. 70, 4335-4345 (2010).

168. Santegoets, S. J. et al. Myeloid derived suppressor and dendritic cell subsets are related to clinical outcome in prostate cancer patients treated with prostate GVAX and ipilimumab. J. Immunother. Cancer 2, 31 (2014)

169. Meloni, F. et al. Foxp3 expressing $\mathrm{CD}^{+} \mathrm{CD} 25^{+}$and $\mathrm{CD} 8{ }^{+} \mathrm{CD} 28^{-} \mathrm{T}$ regulatory cells in the peripheral blood of patients with lung cancer and pleural mesothelioma. Hum. Immunol. 67, 1-12 (2006).

170. Miller, A. M. et al. CD4 ${ }^{+}$CD $25^{\text {high }}$ T cells are enriched in the tumor and peripheral blood of prostate cancer patients. J. Immunol. 177, 7398-7405 (2006).

171. Maruyama, T. et al. Distribution of $T_{H} 17$ cells and FoxP3 ${ }^{+}$regulatory $\mathrm{T}$ cells in tumor-infiltrating lymphocytes, tumor-draining lymph nodes and peripheral blood lymphocytes in patients with gastric cancer. Cancer Sci. 101, 1947-1954 (2010).

172. Ichihara, F. et al. Increased populations of regulatory $\mathrm{T}$ cells in peripheral blood and tumor-infiltrating lymphocytes in patients with gastric and esophageal cancers. Clin. Cancer Res. 9, 4404-4408 (2003).

173. Ormandy, L. et al. Increased populations of regulatory $T$ cells in peripheral blood of patients with hepatocellular carcinoma. Cancer Res. 65 2457-2464 (2005).

174. Liyanage, U. K. et al. Prevalence of regulatory $T$ cells is increased in peripheral blood and tumor microenvironment of patients with pancreas or breast adenocarcinoma. J. Immunol. 169, 2756-2761 (2002).

175. Schluter, J. et al. The gut microbiota is associated with immune cell dynamics in humans. Nature $\mathbf{5 8 8}$ 303-307 (2020)

176. Routy, B. et al. Gut microbiome influences efficacy of PD-1-based immunotherapy against epithelial tumors Science 359, 91-97 (2018).

177. Gopalakrishnan, V. et al. Gut microbiome modulates response to anti-PD-1 immunotherapy in melanoma patients. Science 359, 97-103 (2018).

178. Matson, V. et al. The commensal microbiome is associated with anti-PD-1 efficacy in metastatic melanoma patients. Science 359, 104-108 (2018).

179. Mager, L. F. et al. Microbiome-derived inosine modulates response to checkpoint inhibitor immunotherapy. Science 369, 1481-1489 (2020).

180. Tanoue, T. et al. A defined commensal consortium elicits CD8 T cells and anti-cancer immunity. Nature 565, 600-605 (2019).

181. Fessler, J., Matson, V. \& Gajewski, T. F. Exploring the emerging role of the microbiome in cancer immunotherapy. J. Immunother. Cancer 7, 108 (2019).

\section{Acknowledgements}

The authors acknowledge funding support from National Institutes of Health (NIH) grant DP5 OD023056, the Parker Institute for Cancer Immunotherapy and the Chan Zuckerberg Biohub to M.H.S.

\section{Author contributions}

The authors contributed equally to all aspects of the article.

\section{Competing interests}

M.H.S is a co-founder and board member of Teiko Bio, receives research funding from Roche/Genentech, BristolMyers Squibb and Valitor, and has been a paid consultant for Earli, Five Prime Therapeutics, Ono Pharmaceutical and January Inc. B.M.A. is currently an employee of Teiko Bio. K.J.H.-G. declares no competing interests.

\section{Peer review information}

Nature Reviews Cancer thanks N. Chaput, T. Merghoub and the other, anonymous, reviewer(s) for their contribution to the peer review of this work.

\section{Publisher's note}

Springer Nature remains neutral with regard to jurisdictional claims in published maps and institutional affiliations.

C) Springer Nature Limited 2021 